Review

\title{
Development of gold catalysts supported by unreducible materials: Design and promotions
}

\author{
Jingjie Luo a, Yanan Dong a, Corinne Petit ${ }^{b}$, Changhai Liang a,* \\ a Lab of Advanced materials \& Catalytic Engineering (AM\&CE), School of Chemical Engineering, Dalian University of Technology, Panjin 124221, Liaoning, \\ China \\ b Institut de Chimie et Procédés pour l'Energie, l'Environnement et la Santé (ICPEES), UMR 7515 CNRS, University of Strasbourg 25, rue Becquerel, 67087 \\ Strasbourg cedex 02, France
}

\section{A R T I C L E I N F}

\section{Article history:}

Received 26 April 2020

Accepted 14 June 2020

Available online 22 September 2020

\section{Keywords:}

Gold catalyst

Unreducible support

Promotion

Au-support interfaces

Synergy effect

\begin{abstract}
A B S T R A C T
Gold catalysis had been considered a highly efficient candidate for heterogeneous catalysis. It is well established that reducible-material-supported Au NPs are more reactive than the unreducible materials, unless specific modifications are carried out. However, unreducible materials such as carbon materials, silica, and alumina have particular advantages, including the easily controlled surface property, adjustable microscopic structure, earth-abundant reserves, and facile industrial manufacture. New strategies, influences, and mechanisms of modification to enhance the catalytic performance and thermal stability of unreducible-material-supported gold catalysts are among the most attractive research topics in gold catalysis. However, to the best of our knowledge, reports and reviews focused on unreducible-material-supported gold catalysts are lacking. Herein, the above concept will be thoroughly discussed regarding several typical unreducible supports, including the commonly used silica, alumina, carbon materials, and hydroxyapatite. The currently prevailing modification strategies will be summarized in detail from the aspects of theoretical conceptualization and practical methodology, including the ingenious synthesis method for catalyst with a specific structure, the currently prosperous electrostatic adsorption, colloid immobilization, and the applicative thermal gaseous treatment. The influences of physical and chemical modifications on the surface chemistry, electronic structure, interaction/synergy between Au-support/promoter, catalyst morphology and water precipitation will be also summarized. It is assumed that the review will shed light on significant studies on unreducible support in gold catalysis with the purpose of catalytic promotion and the promotion of the potential industrial demands in advance. Furthermore, the review will provide new insights into unreducible supports that can be potentially applied in gold catalysis.
\end{abstract}

(C) 2021, Dalian Institute of Chemical Physics, Chinese Academy of Sciences. Published by Elsevier B.V. All rights reserved.

\section{Introduction}

Gold had been considered as one of the most stable metals for thousands of years, until the 1980s when Haruta et al. [1] reported that supported gold nanoparticles (Au NPs) facilitated super-active $\mathrm{CO}$ oxidation. The application of Au NPs in chemistry was then developed, and nano-scale gold materials as indispensable catalyst materials were introduced $[2,3]$. The

\footnotetext{
* Corresponding author. Tel/Fax: +86-411-84986353; E-mail: changhai@dlut.edu.cn This work was supported by the National Natural Science Foundation of China (21573031, 21802015, 21978031), Program for Excellent Talents in Dalian City (2016RD09), and the Fundamental Research Funds for the Central Universities (DUT20RC(5)020).

DOI: 10.1016/S1872-2067(20)63743-3 | http://www.sciencedirect.com/science/journal/18722067 | Chin. J. Catal., Vol. 42, No. 5, May 2021
} 
investigations of supported nano-scale gold catalysts have received considerable attention. An appropriate target reaction, using nano-scale gold material as a catalyst, might contribute to enhancing the selectivity and yield of target products under the same operating conditions, or allow mild reaction conditions with only a small amount of catalyst [4]. Using gold catalysts has potential to lower cost, save energy, and facilitate improved industrial manufacture in the near future [5].

The supporting material for Au NPs is one of the most important factors for the performance of gold catalysts. It is essential for the regulation of the sizes and shapes of particles, the chemical compositions, the exposed active sites, and the synergy/perimeters formed at the interface of the Au-support. Reported supports for Au-NPs can be divided into two groups according to whether it is reducible or not, in most cases. Active/reducible supports generally consist of metal oxides with well-defined reducibility and may contribute to the reaction process by the storage and release of oxygen either in $\mathrm{O}_{2}$ rich or lean conditions [6-9]. On the contrary, inert supports are mainly unreducible metal oxides, such as $\mathrm{SiO}_{2}$ and $\mathrm{Al}_{2} \mathrm{O}_{3}$, together with carbon materials and other non-metal oxides such as hydroxyapatite and ceramics, which are reported to be less preferential to support Au NPs [10,11]. The investigations of diverse materials such as silica and carbon materials revealed that such kinds of materials have superior advantages and accordingly, they have become widely used industrial supports compared with the traditional reducible metal oxides, due to their earth-abundant reserves, toughness, easily tuned surface chemistry, controllable electronic and structural properties, and diverse morphologies that are easily synthesized [12-14]. On the contrary, traditional reducible oxides as supports are well-defined and their further applications are narrowed due to high cost and limited reserves. Furthermore, basic investigations involving metal-support interaction and reaction mecha- nism based on combining effect from both gold and support will be simplified using unreducible supports. Fortunately, unreducible supports, with promotion, can also be potentially applied as appropriate carriers for Au NPs [15-18]. The promotion and selection of materials for supporting gold have become the fundamental study focus in catalysis. The most developed strategies are summarized in Fig. 1. The mainstream methods include the atomically dispersed single-atom/site $\mathrm{Au}$, fine Au NPs captured by surface functional groups, the introduction of secondary metal species to form anchorage sites for $\mathrm{Au}$, alloy structures, inversely supported $\mathrm{MO}_{x} / \mathrm{Au}$ catalysts, and other bimetallic structures of atomic-scale [19-22].

Many constructive reviews have focused on gold catalysis in organic and inorganic reactions, the gold-support interaction, and innovative preparation of gold catalysts [23-26]. However, to the best of our knowledge, there is still no review concerning the modification strategies and their function in gold catalysts using unreducible supports as a study model. In order to provide a comprehensive understanding of unreducible supports potentially applied in gold catalysis and the valid strategy to promote unreducible supports as materials comparable to reducible metal oxides, here we review systematically both the conventional and currently adopted unreducible supports for gold catalysis. This review will provide a summary based on the research work focused on the unreducible supports used for gold catalysts, including the current promotion strategies, their influences on the chemical and surface properties of gold catalysts, and the variation of reaction mechanisms. Mindful of the space restrictions, we will first provide a general insight into the investigations and then representative samples and results will be reviewed in detail. In this review, we will focus on the investigations during the past decades concerning the modification of the structure and performance based on Au NPs supported by typical unreducible metal oxides.

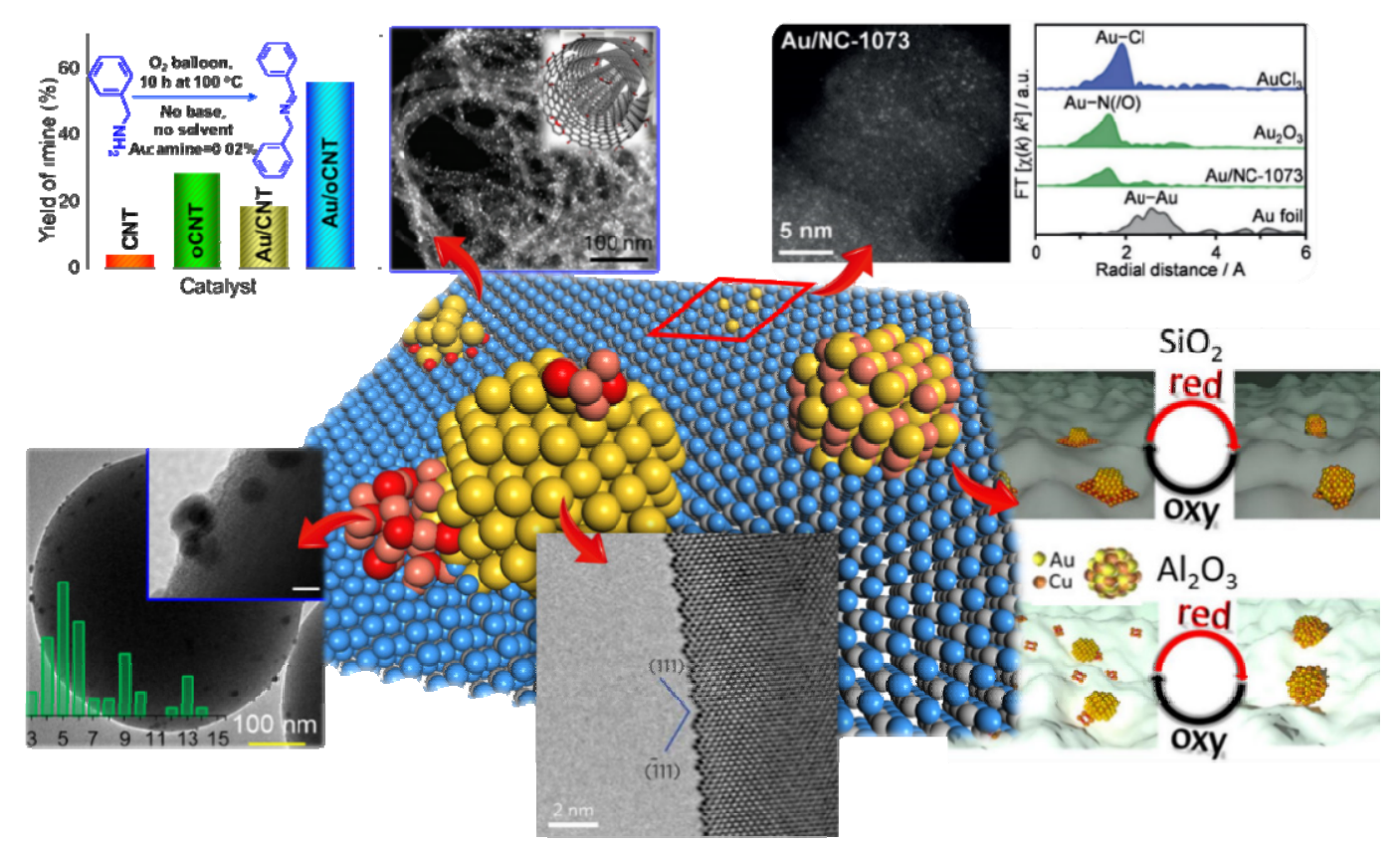

Fig. 1. Unreducible-carrier-supported Au NPs and prevailing modification strategies in current research [19-22,27,28]. 


\section{Typical unreducible materials and gold}

Researchers have argued that only extraordinarily weak interactions can be generated between gold and unreducible supports if the traditional wet impregnation method is applied. In general, the deposition-precipitation method is also inadequate for the preparation of Au NPs supported with unreducible materials with a low IEP (isoelectric point) (e.g., silica, with IEPSilica $_{2} 2.0$ ). Besides, small Au NPs formed on the surface of unreducible support during the synthesis may easily agglomerate during the calcination and reaction processes, leading to fierce deactivation of the catalyst. However, even for Au NPs supported on active reducible supports such as $\mathrm{FeO}_{x}$ and $\mathrm{CeO}_{2}$, challenges persist due to the intrinsic properties of both the $\mathrm{Au}$ NPs and support that cause drawbacks or even deactivation of gold catalysts. Factors inducing deactivation of the catalyst mainly include carbonate-like species accumulation, morphology changes of Au NPs, chloride residue, and unstable support variations that might occur in both unreducible and active-carrier-supported Au NPs [29-32]. However, modification of the surface and structure with high stability to disperse gold particles with maximized exposure of active sites is able to provide unreducible supports as competent carriers comparable to reducible metal oxides. Herein, the most frequently used unreducible supporting materials will be discussed in the following paragraphs to provide a general insight.

\subsection{Alumina and gold}

Three main crystalline phases of alumina commonly used in the catalytic systems include the $\alpha-\mathrm{Al}_{2} \mathrm{O}_{3}, \beta-\mathrm{Al}_{2} \mathrm{O}_{3}$, and $\gamma-\mathrm{Al}_{2} \mathrm{O}_{3}$, where $\gamma-\mathrm{Al}_{2} \mathrm{O}_{3}$ can be transformed into $\alpha-\mathrm{Al}_{2} \mathrm{O}_{3}$ with thermal treatment under $950-1200{ }^{\circ} \mathrm{C}$. Conventional impregnation or the deposition-precipitation method cannot facilitate the dispersion of fine gold particles on $\mathrm{Al}_{2} \mathrm{O}_{3}$. We have previously synthesized $\mathrm{Au} / \mathrm{Al}_{2} \mathrm{O}_{3}$ via the deposition-precipitation method using urea as a precipitator [33]. The average size of Au NPs reached approximately $6 \mathrm{~nm}$ after the calcination process, mainly due to the weak interaction between gold and alumina. The $\mathrm{Au} / \mathrm{Al}_{2} \mathrm{O}_{3}$ thus displayed inferior catalytic activity for $\mathrm{CO}$ oxidation with $100 \% \mathrm{CO}$ conversion even higher than $400{ }^{\circ} \mathrm{C}$. In fact alumina is still one of the most highly disputed unreducible supports. Alumina-supported Au NPs were reported to exhibit poor activity, although it turned out to be a promising candidate if used in the preferential oxidation of $\mathrm{CO}$ in $\mathrm{H}_{2}$, due to the fact that the apparent activation energy of $\mathrm{CO}$ oxidation is lower than that of $\mathrm{H}_{2}$ oxidation [34]. Moreover, catalysts based on the dispersion of precious metals with an appropriate modification could be efficient. Li et al. [35] also reported the novel aerogel supported Au NPs by a gold precursor capped by APTES, where hydrolyzation/co-condensation of the APTES and aluminum alkoxide occurred during the synthesis. The as-formed $\mathrm{Au} / \mathrm{SiO}_{2} @ \mathrm{Al}_{2} \mathrm{O}_{3}$ displayed enhanced thermal stability. Au NPs are trapped in and physically protected by the framework of the alumina aerogel, providing excellent thermal stability with no observable sintering at $650{ }^{\circ} \mathrm{C}$. The aerogel supported Au NPs exhibited much better activity for sol- vent-free aerobic benzyl alcohol oxidation than conventional alumina supported gold catalysts.

The catalytic performance of alumina supported Au NPs can be enhanced by introducing a suitable amount of a promoter such as a metal oxide. Roselin et al. [36] synthesized Au NPs supported by $\mathrm{FeO}_{x}-\mathrm{Al}_{2} \mathrm{O}_{3}$ for the selective production of hydrogen by partial oxidation of methanol (POM), and superior activity was reported compared to gold supported on a pure $\mathrm{Fe}_{2} \mathrm{O}_{3}$ support or the $\mathrm{Fe}_{2} \mathrm{O}_{3}-\mathrm{ZrO}_{2}$. This study suggested that the positively charged gold species in the samples were related to the highly dispersed gold composites and responsible for a complete transformation of methanol at only $250{ }^{\circ} \mathrm{C}$ with $48 \% \mathrm{H}_{2}$ selectivity. More precisely, alumina with suitable modification facilitated the fine dispersion of gold species against sintering, even matching up with the reducible support.

\subsection{Silica and gold}

Silica is another kind of earth-abundant material with low price and very good stability in acid; thus, it was chosen as one of the potential unreducible supports for Au NPs. However, the activity of $\mathrm{Au} / \mathrm{SiO}_{2}$ synthesized by impregnation or the deposition-precipitation method was inactive for $\mathrm{CO}$ oxidation either due to the larger aggregations or the unsuccessful loading of $\mathrm{Au}$ NPs, mainly caused by the low isoelectric point and surface acidity. One of the efficient strategies is to enhance the Au deposition by promoted preparation procedures. The initial method proposed by Haruta et al. [37] was named as chemical vapor deposition (CVD). An acetylacetonate complex of gold $\left(\left(\mathrm{CH}_{3}\right)_{2} \mathrm{Au}\left(\mathrm{CH}_{3} \mathrm{COCH}_{2} \mathrm{COCH}_{3}\right)\right)$ was used as a precursor, which evaporated through the reaction vessel and was adsorbed by the pre-purified metal oxide, including $\mathrm{Al}_{2} \mathrm{O}_{3}, \mathrm{SiO}_{2}$, and $\mathrm{TiO}_{2}$, respectively. The catalytic performances for $\mathrm{CO}$ oxidation by $\mathrm{Au} / \mathrm{Al}_{2} \mathrm{O}_{3}$ and $\mathrm{Au} / \mathrm{SiO}_{2}$ can match that of $\mathrm{Au} / \mathrm{TiO}_{2}$. It was also suggested that the catalytic performances mainly depended on the interaction between gold and support, instead of the nature of support itself under $0{ }^{\circ} \mathrm{C}$. Our previous work also focused on Au NPs fixing on non-porous spherical silica by a colloid immobilization strategy. The colloidal Au NPs can be loaded onto the surface of non-porous Stöber silica by adjusting the $\mathrm{pH}$ to approximately $1.0[21,27]$. However, the limitation of $\mathrm{Au}$ mass loading remained, and the application of $\mathrm{Au} /$ Stöber silica for CO oxidation was still unsatisfactory [21].

On the other hand, silica with an ordered structure was also beneficial for the selective passing and adsorption of specific reactants/intermediates, the exposure/maintaining of active sites, and the formation of the target products. The mesoporous structure of these silica materials can be regulated by the ratio between reactants and reaction conditions. Typical silica materials include ZSM-5, SBA-15, and MCM-41 [38-41]. Flytzani-Stephanopoulos and coworkers [42] dispersed single-site gold species $\mathrm{Au}-\mathrm{O}(\mathrm{OH})_{x^{-}}(\mathrm{Na}$ or $\mathrm{K})$ stabilized by alkali ions on the surface of KLTL-zeolite and MCM-41. Good catalytic performance for the water-gas shift reaction (WGSH) was found at temperatures lower than $200{ }^{\circ} \mathrm{C}$. Special -O linkages with more than eight alkali ions were formed by the gold species, which was comparable to the activity of Pt and played the role of the 
(A)

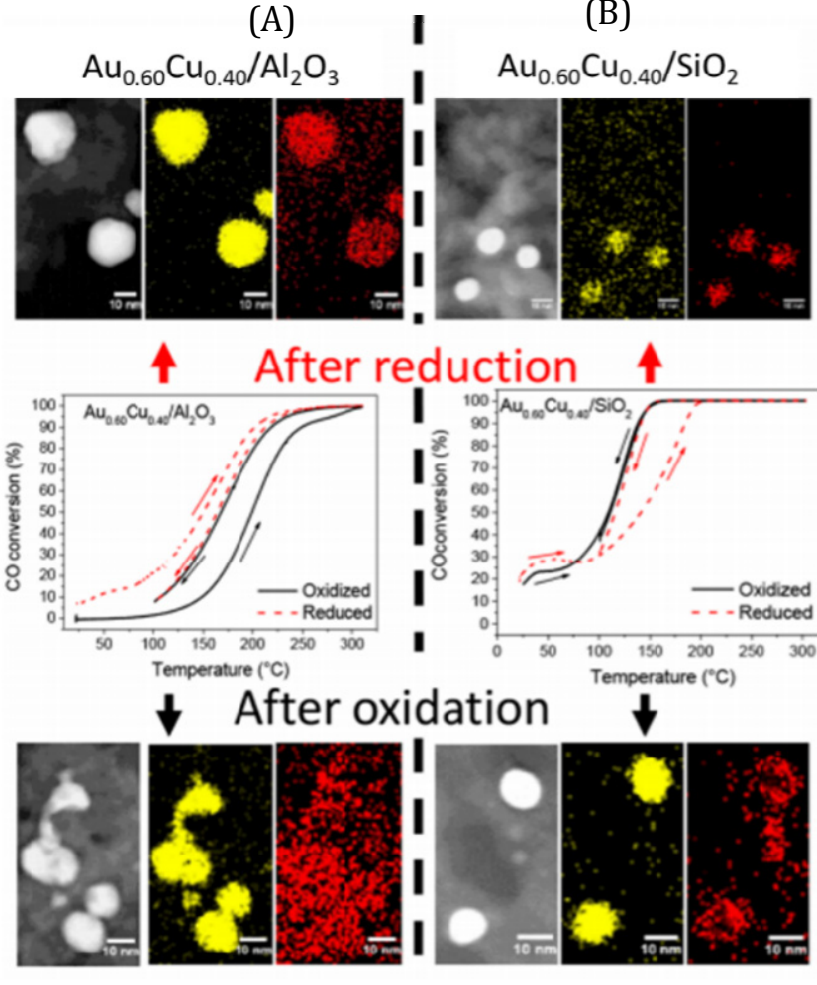

(C)
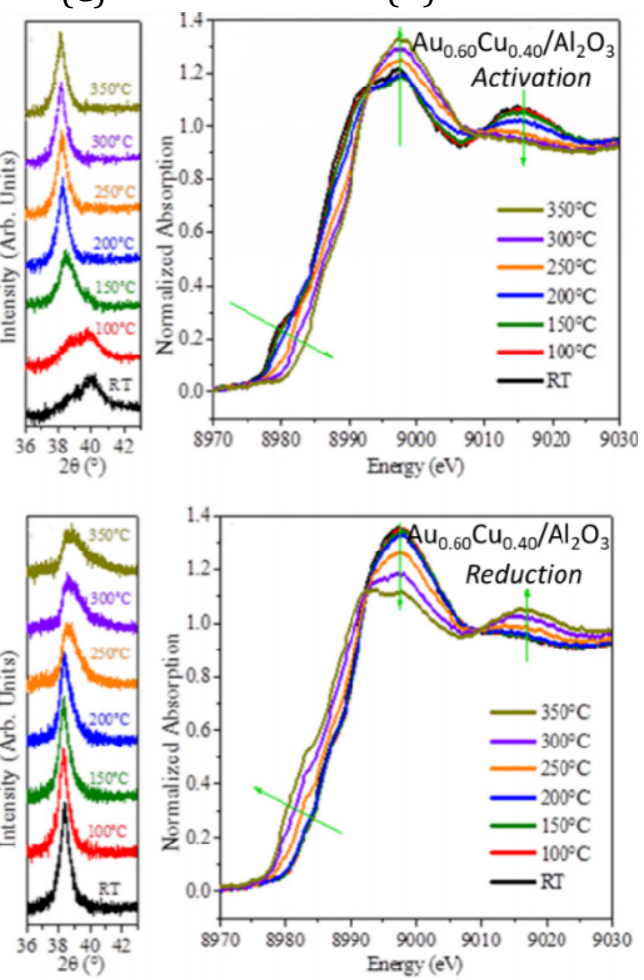

(D)

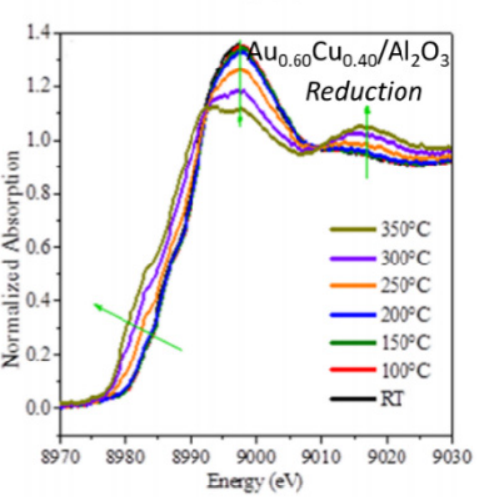

Fig. 2. Catalytic activity in $\mathrm{CO}$ oxidation for the $\mathrm{Au}_{0.60} \mathrm{Cu}_{0.40} / \mathrm{Al}_{2} \mathrm{O}_{3}(\mathrm{~A})$ and $\mathrm{Au}_{0.60} \mathrm{Cu}_{0.40} / \mathrm{SiO}_{2}(\mathrm{~B})$ catalysts after an oxidative or reductive pretreatment. Evolution of the $\mathrm{Au}_{0.60} \mathrm{Cu}_{0.40} / \mathrm{Al}_{2} \mathrm{O}_{3}$ catalysts during the in situ XRD (C) and in situ XANES (D) at Cu $K$-edge during activation (up) and reduction (down) respectively [20].

active site in the WGSH reaction. The mesoporous silica-supported single-site gold species displayed similar activity as $\mathrm{Au}$ NPs supported on reducible supports, with the common and similarly structured gold active sites.

In addition to the above modifications of silica structure, Destro et al. [20] introduced a secondary element- $\mathrm{Cu}$ to fabricate the supported $\mathrm{AuCu}$ alloy, and compared their alloy/phase segregation under different atmospheres using silica and alumina supports. It was found that despite the innocent activity of the pure supports, the $\mathrm{Au}_{1-x} \mathrm{Cu}_{x}$ bimetallic particles played a crucial role in the formation of interface sites by the de-alloying and re-alloying processes (Fig. 2). The $\mathrm{Au}_{1-x} \mathrm{Cu}_{x}$ underwent de-alloying under the oxidation atmosphere and re-alloying under the reduction atmosphere, as confirmed by the in situ XANES spectra at the $\mathrm{Cu} K$-edge. The distinctive de-alloy process that occurred on the $\mathrm{SiO}_{2}$ and $\mathrm{Al}_{2} \mathrm{O}_{3}$ was assumed to be decisive for the formation of $\mathrm{CuO}_{x}$ species and the $\mathrm{Au}-\mathrm{Cu}$ interface. The $\mathrm{CuO}_{x}$ species were promptly isolated on the surface of the alumina and removed from the Au NPs, while tightly neighbored with $\mathrm{Au}$ NPs on $\mathrm{SiO}_{2}$. The different formation of the $\mathrm{Au}-\mathrm{Cu}$ interface and the perimeter was in turn responsible for the catalytic performance with respect to $\mathrm{CO}$ oxidation. The $\mathrm{Au}_{1-x} \mathrm{Cu}_{x} / \mathrm{SiO}_{2}$ exhibited much better activity with $50 \%$ CO conversion at $110^{\circ} \mathrm{C}$.

\subsection{Carbon and gold}

Carbon materials include the activated carbon (AC), carbon nanotubes (CNT), nanodiamonds (ND), carbon nanofibers (NF), graphite, and graphene [43]. Outstanding thermal and electrical conductivity, as well as their particular properties related to the spatial structure (from 0 to 3-dimensional materials, as shown in Fig. 3) are the most promising properties compared to other active/inert materials. They have been used for a long time as valuable supports for precious metals such as $\mathrm{Pt}, \mathrm{Pd}$, and $\mathrm{Ru}$ [44-48].

Malta and co-workers [49] supported 1 wt $\% \mathrm{Au}$ sub-nanoclusters on the surface of carbon impregnated in $\mathrm{HAuCl}_{4}$ dissolved by either aqua regia, $\mathrm{HNO}_{3}$, or $\mathrm{H}_{2} \mathrm{O}$, which displayed rational catalytic performance for acetylene hydro-

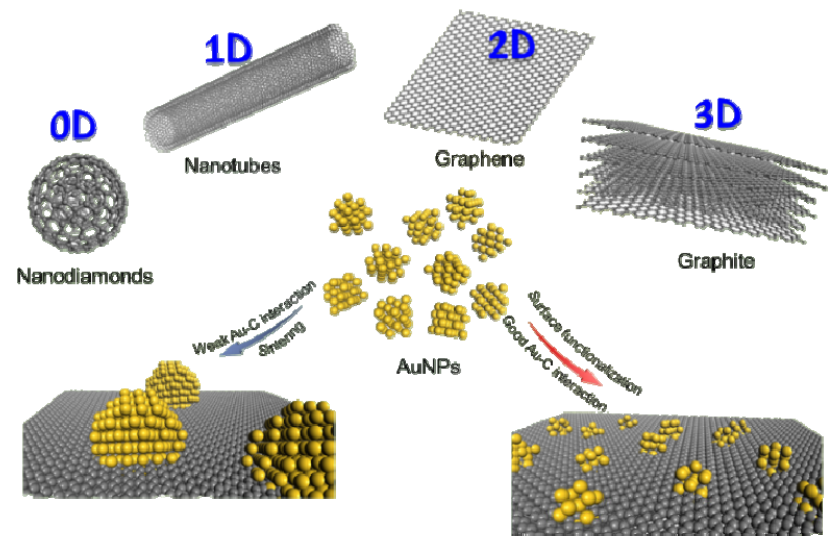

Fig. 3. Illustration of carbon materials with different dimensions used as inert supports for gold. 
chlorination. An in situ X-ray absorption fine structure study of the catalysts was carried out under reaction conditions. Results suggested that single-site cationic Au existed and the ratio of $\mathrm{Au}^{+}$to $\mathrm{Au}^{3+}$ accounted for the related catalytic activity. However, most carbon materials used as supports for small Au NPs require further improvement.

Seral-Ascaso et al. [50] compared the catalytic activity and chemical properties of various carbon materials, including graphene, carbon black, carbon nanotubes, and nanodiamonds, for the hydroamination of alkynes. It was suggested that graphene displayed better performance in terms of conversion values, mainly due to the larger BET surface areas, well-developed mesoporosity, and good dispersibility in water during the decoration process with Au NPs. It was also confirmed that the surface oxygen-functionalized groups (44.9 wt $\%$ o content, including hydroxyl, carbonyl, phenol, and epoxide groups) in graphene and nanodiamonds are in charge of the smaller sizes and dispersion of Au NPs, as well as the enhanced catalytic activity.

Another indispensable advantage of carbon materials is their easily tuned surface properties. The surface chemistry of carbon materials has been considered as one of the most important factors for reactions. Xu et al. [51] synthesized Au NPs on activated carbon (AC) with different formations of surface oxygenated groups. The $\mathrm{Au}^{3+}$ species proved as efficient active species for acetylene hydrochlorination in the gold-C composite. The formation of the total amount of oxygenated groups, including carbonyl, phenol, and ether groups, was confirmed to be essential for the catalytic performance and the stabilization of $\mathrm{Au}^{3+}$ species. Furthermore, the function of oxygenated groups also relies on the targeted reactions and demanded products. Rodrigues et al. [52] also engaged in similar work. They investigated the influence of surface oxygenated groups of $\mathrm{Au} / \mathrm{AC}$ on the catalytic performance of glycerol oxidation. Both the average sizes of Au NPs and the textural properties were controlled to avoid the additional size and structure effects. Although it was also suggested that the surface oxygenated groups displayed significant roles in the reaction, it was further confirmed that basic oxygen-free support was responsible for the promoted catalyst with a higher density of free $\pi$-electrons and better electron mobility. However, the acid oxygenated groups on the surface of $\mathrm{Au} / \mathrm{AC}$ were disadvantageous to the catalytic performance of glycerol oxidation.

Although it has been reported that Au NPs can be supported on carbon materials such as graphene and specific mesoporous carbon [53], it is still challenging to disperse fine Au NPs on the surface of most carbon materials especially carbon nanotubes and activated carbon. Sá et al. [54] provided the possibility of small Au NPs captured by AC modified with methyl halide. It was suggested that Au NPs supported on AC by the common method were as large as $20 \mathrm{~nm}$, and greatly reduced to sub-nanoclusters after the AC was preliminarily treated by $\mathrm{CH}_{3} \mathrm{I}$. However, $\mathrm{Au} / \mathrm{AC}$ treated by $\mathrm{CH}_{3} \mathrm{I}$ did not display good catalytic performance during ethanol dehydrogenation. Nevertheless, $\mathrm{CH}_{3} \mathrm{I}$ treatment successfully induced the deposition of small $\mathrm{Au}$ NPs on the carbon surface, and provided a new strategy for dispersion of gold on carbon materials. In our recent work, small Au NPs of approximately 2-3 nm were successfully deposited on carbon material (CNTs) by the colloid immobilization method only after preliminary functionalization of the CNTs by ozone [28]. The sizes of Au NPs can be maintained at approximately $4 \mathrm{~nm}$ after calcination under air at $300{ }^{\circ} \mathrm{C}$ for 3 $\mathrm{h}$, which were confirmed active for the coupling oxidation of benzylamine. The Au/C-AQ catalyst with an extraordinary amount of gold loading ( $55 \mathrm{wt} \%$ ) by the aqueous phase method without any organic stabilizing agent was designed and synthesized for the first time by our colleagues (Fig. 4) [55]. Potassium sulfate solution $(0.4 \mathrm{M})$ was applied as a precipitant to change the polarity of carbon and to facilitate the deposition of Au NPs. The average particle size of gold was approximately 4.7 $\mathrm{nm}$, which was only slightly larger than that of the Au/C-NC synthesized in the presence of organic compounds1-octadecene and oleylamine. The as-synthesized $\mathrm{Au} / \mathrm{C}-\mathrm{NC}$ and $\mathrm{Au} / \mathrm{C}-\mathrm{AQ}$ could be further applied in the electro-oxidation reactions of glycerol. Very close tartronate yields were obtained by using Au/C-AQ and Au/C-NC (61.2\% and 61.8\%) samples. The conversion rate of glycerol by $\mathrm{Au} / \mathrm{C}-\mathrm{AQ}$ reached $95.6 \%$ within $12 \mathrm{~h}$ and was clearly faster than that of $\mathrm{Au} / \mathrm{C}-\mathrm{NC}$ (89.2\%), resulting in higher electrical energy generation (1666 J vs. 1527 J). Most importantly, it was confirmed that high loading and surface dispersion of gold can be obtained in the absence of organic coupling agents, with the alternative catalytic performance, providing an innovative perspective of gold-carbon materials in the catalysis world.

Furthermore, nanodiamonds (ND) are also a kind of special carbon materials with a particle diameter of approximately 4-5 $\mathrm{nm}[56,57]$. In particular, the presence of crystalline carbon with hybrid orbitals allows the ND to exhibit unexpected surface activities. The ND with $s p^{2}$ carbon layer has a large surface-to-volume ratio and functionalized groups, and can be used as efficient non-metal catalysts [58,59]. Alternatively, Pt or Pd NPs supported on NDs with the presence of metal-sp $p^{2}$-carbon bonds might act as active sites with significantly modified chemical bonds of $s p^{2}$ carbons, as well as the binding affinity of the substrates $[60,61]$.

However, there are relatively few reports focused on ND with supported Au NPs. Kim et al. [62] synthesized the novel gold-ND composite by the in situ chemical reduction method, used for the oxidation of o-phenylenediamine in the presence of hydrogen peroxide. Remarkably, neither Au NPs nor ND displayed detectable catalytic activity for the reaction. Only the novel ND-Au composite could produce 2,3-diaminophenazine. The study findings indicated that NDs combined with Au NPs can be a good catalyst. Charge transfer could also be generated at the interfaces of $\mathrm{Au}$ and ND that facilitated the adsorption of the substrate. However, it was challenging for Au NPs to be finely dispersed on the surface of ND. Thus, in depth effective strategies are still required for the design of small $\mathrm{Au}$ NPs/nanoclusters anchored on materials such as ND with anti-sintering properties for structure-sensitive reactions in further work.

Compared to the other carbon materials, graphene or graphene oxide (GO) is more widely used for anchoring fine $\mathrm{Au}$ NPs in the catalysis field [63-65]. Shao and coworkers [66] 

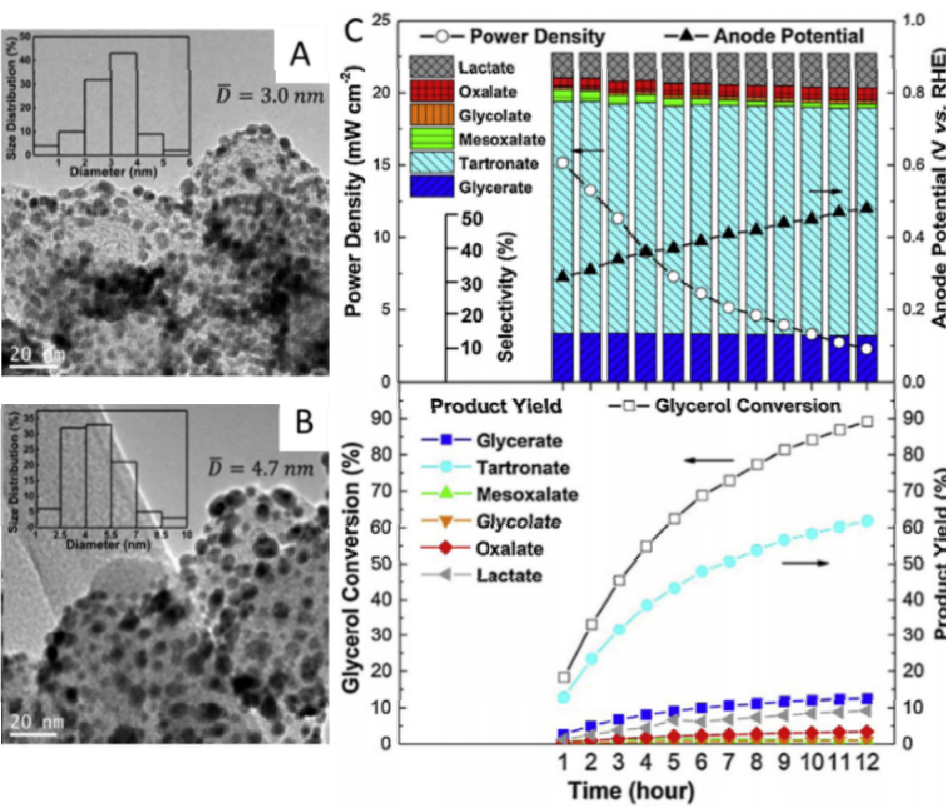

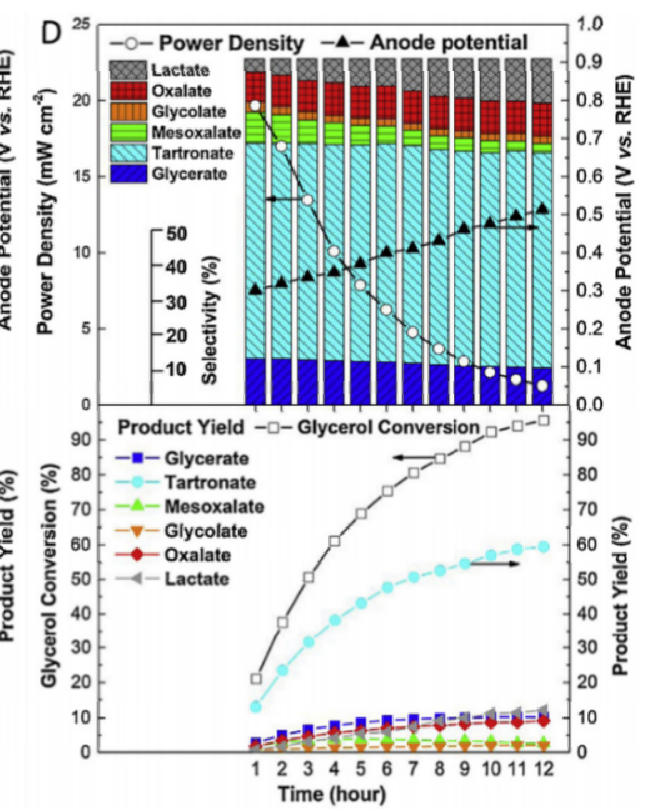

Fig. 4. TEM images of Au NPs on activated carbon with extraordinary gold loading and good distribution of Au NPs in Au/C-NC (A) and Au/C-AQ (B); Electro-catalytic selective oxidation of glycerol on Au/C-NC (C) and Au/C-AQ (D) (55 wt\%) in AEMDGFC under the optimized condition for a high yield of tartronate [55].

studied the dispersed Au NPs on GO surface for the hydrogenation of phenylacetylene. However, although supported Au NPs have been used for oxidation reactions with the appropriate catalytic performance and selectivity of target products, its usage in hydrogenation of alkyne is inferior to most of the supported Pt and Pd NPs in general. However, superior conversion (99\%) and $99 \%$ selectivity of styrene can be obtained at $60{ }^{\circ} \mathrm{C}$ by $\mathrm{Au} / \mathrm{GO}$ catalyst in both continuous flow and batch reactors. The rounded Au NPs with abundant low-coordination sites that were essential for the activation of $\mathrm{H}_{2}$ and adsorption of phenylacetylene, accounted for the excellent catalytic performance. Moreover, the functionalization of GO by reduction was also responsible for the geometrical structure of Au NPs (Fig. 5), the subsurface dynamics of the metallic phase, and the preferential desorption of partial hydrogenation products.

\subsection{Hydroxyapatite and gold}

Hydroxyapatite $\left(\mathrm{Ca}_{10}\left(\mathrm{PO}_{4}\right)_{6}(\mathrm{OH})_{2}, \mathrm{HAP}\right)$ is a kind of non-oxide formed by $-\mathrm{OH}$ and apatite, which is the main composition of human and animal skeletons, and is known as a green and surplus material. Important studies on the modified HAP-supported Au NPs with well-constructed Au-HAP interaction have been reported in recent years $[67,68]$. An earlier report by Domínguez et al. [69] suggested that the HAP has a good capacity to catalyze the oxidation of $\mathrm{CO}$ to $\mathrm{CO}_{2}$ under room temperature, which, however, underwent immediate deactivation along with the increased reaction temperature. They also speculated that the HAP-supported Au NPs could be efficient for $\mathrm{CO}$ oxidation.

The thermal treatment of Au/HAP significantly contributed to the formation of vacancies during elimination of carbonates, which also facilitated the modification of the chemical states of surface gold species. Wang et al. [70] suggested that thermal treatment at $400-600{ }^{\circ} \mathrm{C}$ caused the anchorage of Au NPs. The combination of phosphate groups as well as the - $\mathrm{OH}$ of support contributed to the anti-sintering of Au NPs under lower $(<400$ ${ }^{\circ} \mathrm{C}$ ) and higher temperatures $\left(<600{ }^{\circ} \mathrm{C}\right)$. Tang et al. [68] synthesized Au NPs supported on HAP by the deposition-precipitation method. Reversible encapsulation of Au NPs by the HAP support occurred during the thermal treatment under different atmospheres (Figs. 6(A) and (B)). Electron delivery and CO
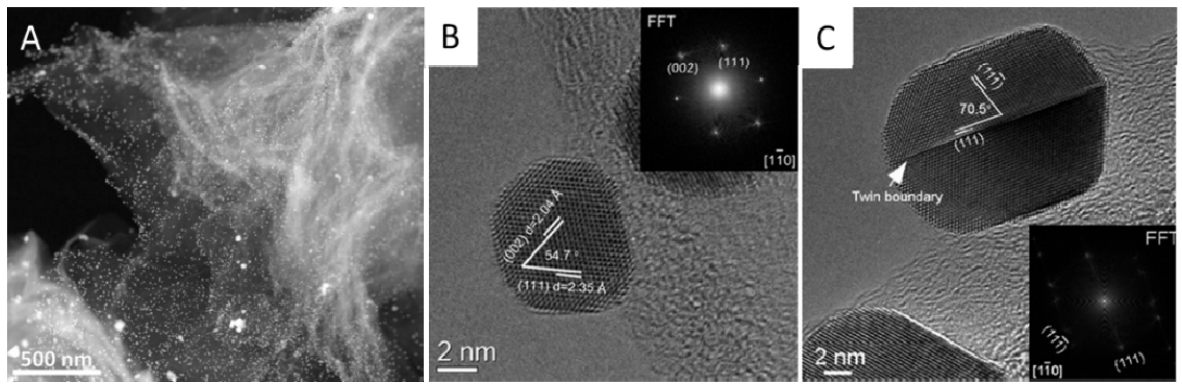

Fig. 5. (A) STEM image of Au/GO before the reaction in fresh status; (B) HRTEM image of an AuNP on GO; (C) HRTEM image of an AuNP on GO after prolonged reduction treatment, with an inset of the fast Fourier transform [66]. 

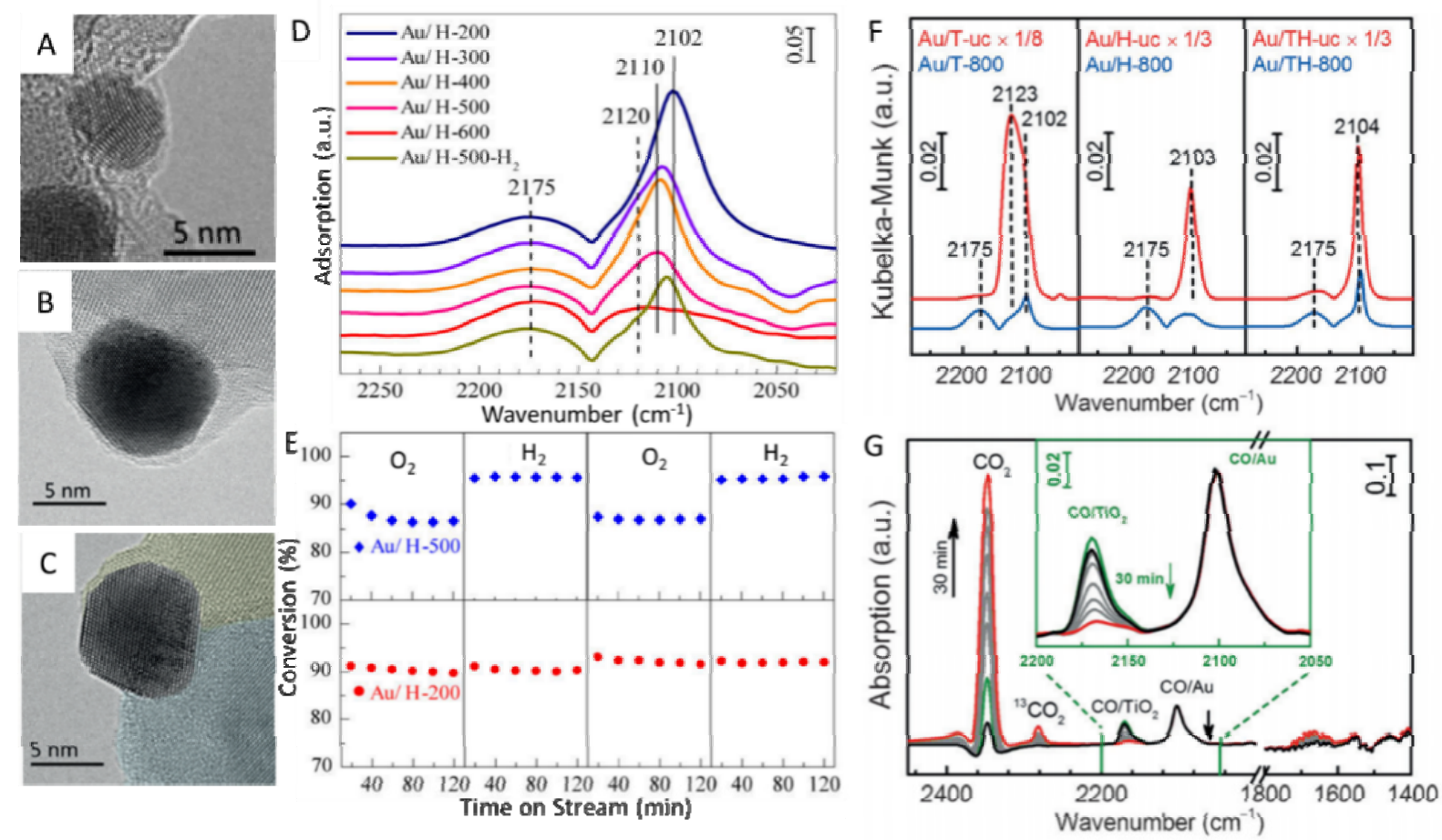

Fig. 6. TEM images of $\mathrm{Au} / \mathrm{H}-600(\mathrm{~A}), \mathrm{Au} / \mathrm{H}-800$ (B), and $\mathrm{Au} / \mathrm{TH}-800(\mathrm{C})\left(\mathrm{H}\right.$ : HAP, $-\mathrm{X}$ : calcination temperature in $\left.{ }^{\circ} \mathrm{C}\right)$; (D) In situ DRIFT spectra of CO adsorption on $\mathrm{Au} / \mathrm{H}-\mathrm{X}$ and $\mathrm{Au} / \mathrm{H}-500-\mathrm{H}_{2}$; (E) CO conversions at $100{ }^{\circ} \mathrm{C}$ on $\mathrm{Au} / \mathrm{H}-500$ and $\mathrm{Au} / \mathrm{H}-200$ with the alternative treatment of $\mathrm{O}_{2}$ and $\mathrm{H}_{2}$ flow; $40 \mathrm{mg}$ and $50 \mathrm{mg}$ catalysts were used for $\mathrm{Au} / \mathrm{H}-200$ and $\mathrm{Au} / \mathrm{H}-500$, respectively. Gas flow: 1 vol\% $\mathrm{CO}+1$ vol\% $\mathrm{O}_{2}$ balanced with $\mathrm{He}, 33.3 \mathrm{~mL} \cdot \mathrm{min}^{-1}$; $(\mathrm{F}$ In situ DRIFT spectra of $\mathrm{CO}$ adsorption on various $\mathrm{Au}$ catalysts at room temperature after 10 min adsorption by $\mathrm{Au} / \mathrm{TH}-800$ ( $\mathrm{TH}$ : $\mathrm{TiO} \mathrm{O}_{2}$ modified $\mathrm{HAP}$ ); (G) The evolution of in situ DRIFT spectra at $-130^{\circ} \mathrm{C}$ after introducing 15 torr $\mathrm{O}_{2}$ to the CO preadsorbed $\mathrm{Au} / \mathrm{TH}-800$ [67,68].

adsorption ability were observed in such a sample. The $\mathrm{Au} / \mathrm{H}-200$ with fully exposed Au NPs underwent metal leaching and severe sintering during the reaction. The $\mathrm{Au} / \mathrm{H}-500$ with partially encapsulated $\mathrm{Au}$ NPs and Au-HAP interaction displayed lower conversion (30\%), but much higher selectivity of benzaldehyde (85\%). The Au NPs in such a sample (Au/H-500) were capable of resisting sintering during calcination. This work puts forward a new strategy to develop ultrastable Au NPs using the definition of a strong metal-support interaction (SMSI).

Later in their research work [67], the authors aimed at modifying HAP with $\mathrm{TiO}_{2}$ for ultrastable Au NPs. TEM images suggest that Au NPs were preferentially located at the interfaces of $\mathrm{TiO}_{2}$ and HAP (Fig. 6(C)). Strong interaction was formed between $\mathrm{Au}$ and $\mathrm{TiO}_{2}$ after calcination at $800{ }^{\circ} \mathrm{C}$, causing the partial encapsulation of $\mathrm{Au}$ by $\mathrm{TiO}_{2}$. The gold sites on HAP could be exposed and are accessible by the reaction molecules. This strong metal-support interaction (SMSI) was also confirmed by the electron transfer from Au to HAP using DRIFT results (Fig. 6(D)). The adsorption peaks at $2102 \mathrm{~cm}^{-1}$ were ascribed to the $\mathrm{CO}$ molecules linearly adsorbed on the surface of the $\mathrm{Au}^{0}$ species $\left(\mathrm{CO}-\mathrm{Au}^{0}\right)$, whilst the adsorption peak at $2175 \mathrm{~cm}^{-1}$ overlapped with the gaseous phase CO. The adsorption peak at $2102 \mathrm{~cm}^{-1}$ was blue shifted in the sample calcined under higher temperature, suggesting the existence of positively charged $\mathrm{Au}$ species in the sample, which should be a sign of the electron transfer from Au to HAP. The reduced peak intensity ought to be resulted from the lower coverage of CO molecules, mainly due to the partial encapsulation of gold by the HAP layer. Only
$\mathrm{CO}$ in the gaseous phase was detected in the Au/H-600 (calcined at $600{ }^{\circ} \mathrm{C}$ ), suggesting the full encapsulation of Au NPs by the HAP layer.

The appearance of adsorbed $\mathrm{CO}-\mathrm{Au}^{0}$ species in the $\mathrm{Au} / \mathrm{H}-500-\mathrm{H}_{2}$ (after $\mathrm{H}_{2}$ reduction) confirmed the recovery and reversible exposure of gold surfaces under a reducing atmosphere. The treatment-dependent activity under different atmospheres (Fig. 6(E)) also revealed that specific adsorption sites (the exposed $\mathrm{Au}^{0}$ sites) were used as the active sites responsible for the catalytic activity. The Au/TH-800 exhibited impressive ability with $50 \%$ CO conversion at only $27{ }^{\circ} \mathrm{C}$ and strong resistance against sintering at $600{ }^{\circ} \mathrm{C}$ for more than 50 h. In the recent work of Tang et al. [71], the SMSI between precious metal and hydroxyapatite has been extended to the platinum-group metal, and renamed as oxidative strong metal-support interactions (OMSIs), which only happened under thermal treatment in the oxidative atmosphere. The OMSIs led to the excellent stability of Pt and Pd catalysts, which could be efficiently used in the oxidative conditions for the first time.

There are other potential unreducible materials for Au NPs such as the silicides, aluminides, ceramics, and carbides. However, most of them are not commonly used and will not be discussed in detail in the current review.

\section{Current synthesis and modification strategies}

Unreducible materials such as silica, carbon and alumina, are attractive for the application as support due to their low price, availability, and stability. On the one hand, these materi- 
als can be applied as carriers to help study the reaction mechanism (e.g., size effect and promoter effect) of gold catalysts for diverse reactions without limitation from the support effect. On the other hand, they are also able to support Au NPs and show significantly improved catalytic performance with appropriate modifications.

The initial starting point to promote the catalytic performances of gold catalysts is focused on strategies to enhance the dispersion of small Au NPs especially for structure sensitive reactions [72,73]. It was reported that the size effect of Au NPs is of great importance for the performance and catalytic stability for reactions such as CO oxidation [74-76]. Gold within nano-size or even sub-nanosize and single-atom that gives a high percentage of low-coordinated sites could be responsible for super-excellent catalytic performances [77]. However, the abundant low-coordinated sites are more thermodynamically unstable and promptly aggregate or are sintered either by particle coalescence or Ostwald ripening due to the considerable surface free energy [78,79]. The deactivation of Au NPs resulting from the evolution of particles into larger aggregates is one of the main problems. In this case, using a simple but efficient method to modify the interaction/interfaces of $\mathrm{Au}$ and unreducible support is fully justified for the better activity of gold catalysts $[80,81]$. The exposure of active sites, redox properties, and activation/dissociation/desorption abilities of reactants have also been investigated in many reports [82]. Different synthetic strategies have also been proposed for unreducible-material-supported Au NPs or even bimetallic systems. In this section, we will summarize the most commonly used ones for monometallic and bimetallic gold catalysts applied for liquid- and gas-phase oxidation. The following paragraphs will be mainly focused on the recently prevailing modification strategies in detail as well as their influences on the nature of the support and structure of the catalysts.

\subsection{Influence of doping component}

Promotion strategies are diverse and exhibit their specific benefits for advanced gold catalysts supported on unreducible supports. One effective and widely used promotion method is to introduce additional components into the structure of support, e.g., metal (oxide) species and non-metal element (functionalization). Original modification strategies can be conducted by reducible-metal oxides-supported Au NPs. The activity of gold catalyst can be considerably changed by gold inversely supporting metal oxide fractions. In such a system, reducible metal oxide was reported to be made as nanoparticles or sub-nanoclusters supported onto unreducible $\mathrm{Au}(111)$, and displayed excellent performance for the WGS reaction [83,84]. Simultaneously, metals such as $\mathrm{Ag}$ and $\mathrm{Cu}$ interacting more strongly with $\mathrm{O}_{2}$ can be applied as dopants by forming $\mathrm{AgO}_{x}$ and $\mathrm{CuO}_{x}$ on the surface of $\mathrm{Au}$ NPs, which is another form of the inversely supported gold catalysts [85]. The related catalyst systems can be viewed as the original models for metal oxides doped/modified unreducible-material-supported Au NPs. With metal oxide doping, Yamada et al. [86] found that the metal-oxide interfaces played a unique role in the doping system. It was demonstrated that the interfaces in a bimetallic catalyst induced a synergistic effect, which could be directly responsible for the promoted catalytic performance of a catalyst due to the specific properties such as charge transfer, atomic arrangement, and interfacial contact between compositions [87]. The formation of an alloy with secondary metals such as Pd and Pt with gold may also change the properties of the sample at the atomic level and may in turn enhance the activity and stability $[88,89]$. Ballarin et al. [90] used the alkynyl carbamate species to functionalize the supporting materials such as $\mathrm{SiO}_{2}, \mathrm{Al}_{2} \mathrm{O}_{3}$, and $\mathrm{TiO}_{2}$, and then to anchor $\mathrm{Au}$ NPs. It was suggested that the $\mathrm{Au}$ NPs could be directly reduced by the support if $\mathrm{HAuCl}_{4}$ was used as a precursor. Using surface modified silica as support, the highest amount of organic functionalization (12 wt\%) as well as the highest gold loading (3.7 wt\%) can be achieved with large but homogeneous $\mathrm{Au}$ NPs (15 nm) fully consisting of $\mathrm{Au}^{0}$ species. The as-synthesized sample can be employed as a catalyst in the oxidation of alcohols in continuous-flow packed bed reactors with excellent stability. On the other hand, surface functionalization of carbon materials also facilitates the anchoring and fixing of Au NPs during the thermal treatment and reaction processes. In the doping effect, the chemical properties and corresponding catalytic performance of the modified samples evolve volcanically along with the detailed parameters of the surface doping, including the loading of secondary metal (oxide), the intrinsic surface chemistry of the doping composition, and the synthesis strategy. Regarding Au supported on alumina, it was reported that the additional iron oxide as a dopant regulated the formation of Au NPs [91]. An appropriate amount of $\mathrm{FeO}_{x}$ led to the formation of Au clusters mainly located on iron species caused by the reduction of Au single atoms, whilst excessive iron oxide was easily reduced to a- $\mathrm{Fe}_{2} \mathrm{O}_{3}$ and deposited the Au NPs and thus was responsible for a significant decrease in the hydrogenation activity. Although the doping composition may enhance the catalytic performance of supported Au NPs in many cases, the exposure of Au active phases is predominant for the reaction.

\subsection{Specific synthesis for advanced morphology}

In order to be in line with the development of current catalysis, supported gold catalysts are designed to be economical, but with vivid special morphologies and capacities for further development. These materials are designed to be core-shell or yolk-shell structures with the confinement effect, porous material encapsulated $\mathrm{Au}$ particles with outstanding stability, and single-atom/site catalysts with fully applied active sites [92,93].

Although considered as unreducible supports, materials such as silica and carbon can be fabricated to be mesoporous or even with a hollow structure, which can either be coated on the particles as the outer layer or directly confine particles in the mesopores or hollow spaces to protect them from sintering during thermal treatment or reaction under harsh conditions [94]. Chen et al. [95] reported a novel strategy to fabricate graphite spheres with a rigid mesoporous structure using the 3D multicomponent colloidal spheres as a precursor that underwent a multistep process involving the self-assembly, car- 

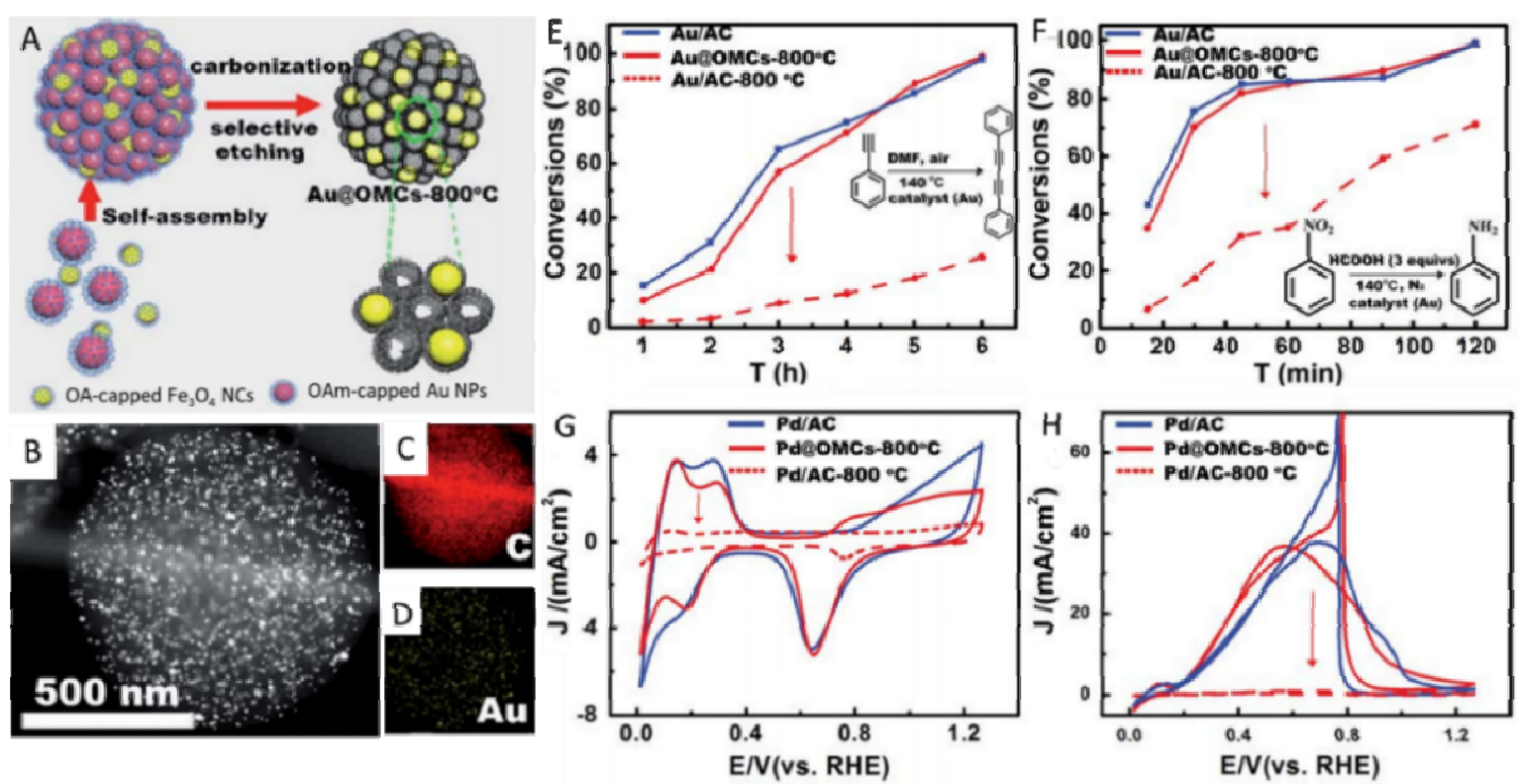

Fig. 7. (A) Schematic of the Au NPs@OMCs- $800{ }^{\circ} \mathrm{C}$ obtained from 3D multicomponent colloidal spheres; (B) HAADF-STEM image of Au@OMCs-800 ㄷ $(\mathrm{C}, \mathrm{D})$ elemental mapping images of $\mathrm{C}, \mathrm{Au}$, and their overlap in Au@OMCs-800 ${ }^{\circ} \mathrm{C}$; (E) Conversion of phenylacetylene homocoupling to 1,4-diphenylbutadiyne; (F) conversion of p-nitrobenzene hydrogenation to phenylamine; (G) CV diagrams for different catalysts scanning between the potentials of $-0.25 \mathrm{~V}$ to $1.0 \mathrm{~V}$ with a scan rate of $50 \mathrm{mV} \cdot \mathrm{s}^{-1}$; $(\mathrm{H})$ specific activity of the formic acid oxidation of different catalysts [94].

bonization, and selective etching. The Au NPs coated by mesoporous carbon layers could also be achieved by carbonization and etching after the self-assembly, as displayed in Figs. 7(A)-(D). The strategy leads to the strong confinement of $\mathrm{Au}$ NPs in the carbon structure, which accounts for the outstanding thermostability, accessibility, and reusability in the organo- and electro-catalysis (Fig. 7(E)-(H)).

$\mathrm{Qu}$ et al. [96] also put forward a convenient method for gold nanoclusters uniformly deposited into the channels of hollow porous carbon nanoparticles (HPCN) by the in situ reduction method. Fig. 8 illustrates the synthesis procedure in detail. The hollow structure can be obtained by emulsion polymerization of the polyaniline-copolypyrrole (PACP) precursor, which displayed excellent thermal stability, well-defined nanostructure,
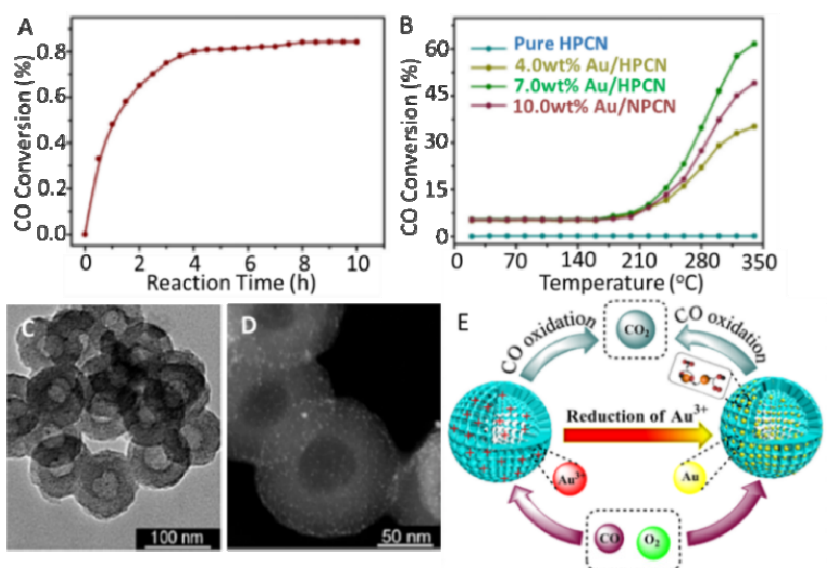

Fig. 8. (A) CO conversion tendency chart during $\mathrm{Au}^{3+}$ ions loading in the pore channels of HPCN; (B) CO conversion tendency chart with increasing temperature from 20 to $340{ }^{\circ} \mathrm{C}$; (C,D) TEM and STEM images of $7.0 \mathrm{wt} \% \mathrm{Au} / \mathrm{HPCN}$; (E) schematic explanation of the preparation of a catalyst and catalytic CO oxidation [96]. and large surface area. The monodispersed Au NPs could be subsequently formed by in situ reduction. The HPCN were beneficial for the cleaning and recycling of the catalyst and the pore channels of HPCN served as a container for the gold nanoclusters. During CO oxidation, CO molecules could be adsorbed and oxygen could be dissociated on the surface of gold facilitated by coordinated gold sites. CO oxidation can be catalyzed by the $\mathrm{Au} / \mathrm{HPCN}$ even during the reduction process of $\mathrm{Au}^{3+}$ ions. Liu et al. [97] synthesized the Au NPs embedded in an ultrathin hollow graphene nanoshell by in situ growth of the graphene layer on the spherical $\mathrm{Au} / \mathrm{TiO}_{2}$ using ethyl benzene as a carbon source and subsequent etching by $\mathrm{NaOH}$. The outer graphene nanoshell was controlled by the coking rate. The as-obtained samples performed exceptional catalytic activity during the reduction of 4-nitrophenol to 4-aminophenol (Fig. 9), which outperformed the reported $\mathrm{Au} / \mathrm{TiO}_{2}$ catalyst and any other $\mathrm{Au}$ and Ag-based catalysts.

\subsection{Electrostatic adsorption and selective chemical deposition}

The electrostatic adsorption strategy is currently a very well-defined method for the synthesis of finely dispersed precious metal particles. The adsorption process can be accomplished between positively and negatively charged composites. In order to facilitate the deposition of gold precursor on the surface of a carrier, it is preferred to change the electronic property of metal precursor or the surface of the support by ion substitution or surface modification by an introduced organic compound. Kraszkiewicz et al. [98] successfully synthesized small $\mathrm{Au}$ NPs supported on mesoporous silica using $\left[\mathrm{Au}(\mathrm{en})_{2}\right] \mathrm{Cl}_{3}$ as the gold precursor. It was suggested that the supported Au NPs were only sub- $2 \mathrm{~nm}$ after thermal treatment under $\mathrm{H}_{2}$ and $\mathrm{O}_{2}$ in sequence. Furthermore, a carbonaceous 

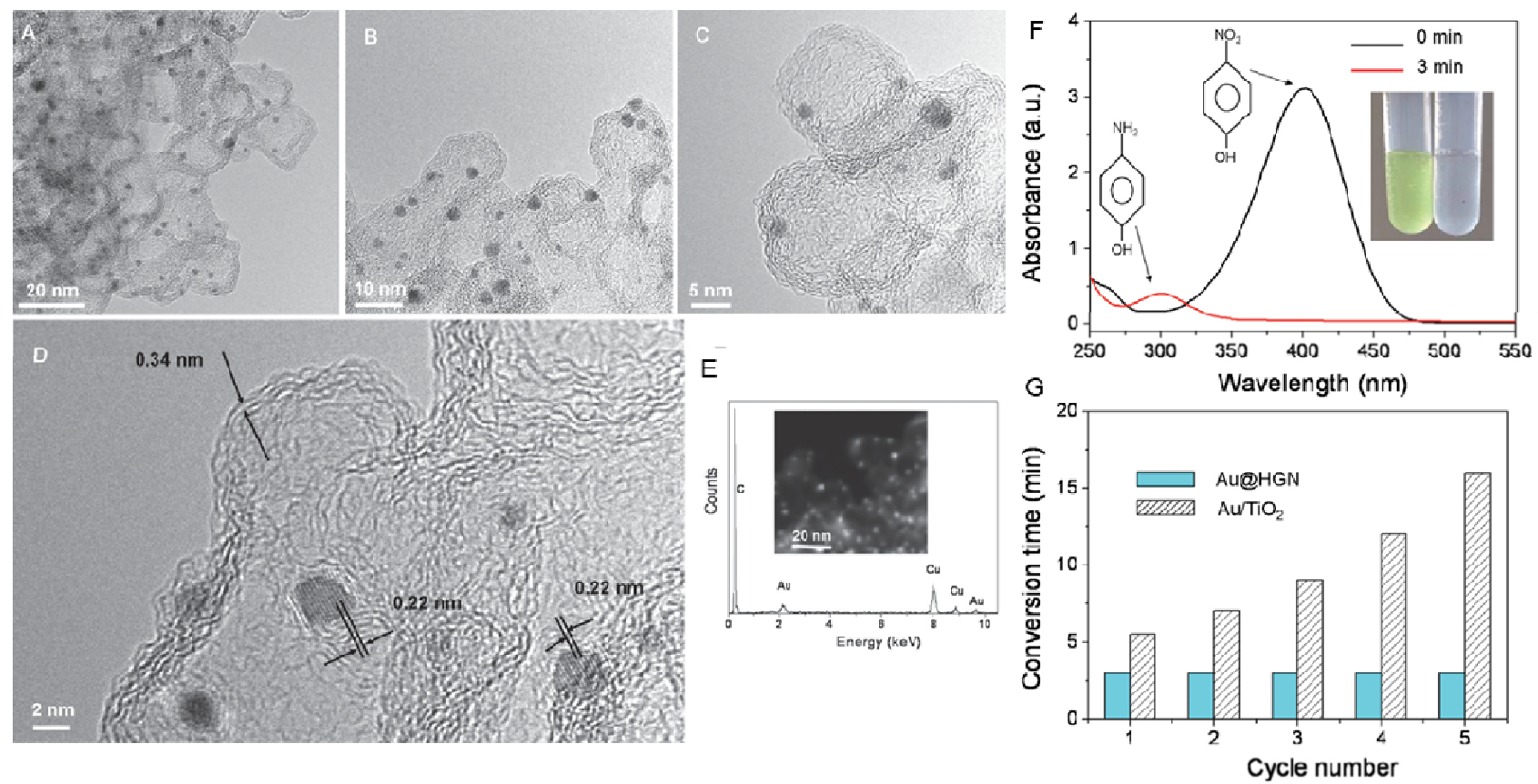

Fig. 9. (A-D) TEM images and high-magnification TEM image of Au NPs embedded into the ultrathin hollow graphene nanoshell (Au@HGN); (E) STEM and EDX results of the Au@HGN nanocomposite; (F) UV/Vis spectra of 4-nitrophenol reduction reaction in the absence and presence of the $\mathrm{Au} @ \mathrm{HGN}$ catalyst. Inset: color changes of the conversion of 4-nitrophenol to 4-aminophenol; (G) The stability of catalysts under the same reduction reaction with five cycles [97].

structure was formed and accounted for the surface stabilization of gold clusters on the support, which was attributed to the decomposition of the ethylenediamine ligand of the gold precursor during $\mathrm{H}_{2}$ treatment. O'Connell et al. [99] successfully synthesized fine Au NPs supported on various carries, including graphitic carbon, silica, and other metal oxides by the electrostatic adsorption method. Small sizes of approximately 1.5 $\mathrm{nm}$ could be obtained with a cationic precursor independent of the nature of the carriers. However, the corresponding catalysts did not exhibit satisfactory activity for the hydrochlorination of acetylene, and even sintering was not found after the reaction. $\mathrm{HCl}$ poisoning was considered as a possible reason.

It is also worth noting that a direct phenomenon caused by electrostatic adsorption is the selective deposition of metal precursor on the target supporting composites, if unreducible carriers with metal oxide promotion were used in the gold system. Early works of Qian and Huang focused on the promotion of $\mathrm{Au}$ /silica by a small amount of metal oxides including $\mathrm{FeO}_{x}$, $\mathrm{MgO}, \mathrm{CeO}_{2}$, etc. [100-102]. The results indicated that Au NPs supported on $\mathrm{CeO}_{2} / \mathrm{SiO}_{2}$ with $6 \mathrm{wt} \% \mathrm{CeO}_{2}$ loading were mainly located on the $\mathrm{CeO}_{2}$ islands instead of a large amount of silica support. Although it was reported that the deposition-precipitation method was applied in this work, the distinctive isoelectric points of silica (approximately 2.0) and $\mathrm{CeO}_{2}$ (approximately 7.0-8.0) were noted. The preliminary deposition of gold precursor $\left(\mathrm{HAuCl}_{4}\right)$ on the surface of $\mathrm{CeO}_{2}$ should be induced by the electrostatic adsorption between the negatively charged gold precursor and the positively charged surface of $\mathrm{CeO}_{2}$. Wu et al. [103] also promoted $\mathrm{Au} / \mathrm{SiO}_{2}$ catalyst by aqueous-phase Fe species. The direct or subsequent introduction of Fe on silica for gold loading was compared to under- stand the impact of the modification of iron species on the structure and catalytic performance of the gold catalyst. The results indicated that both the introduction of $\mathrm{Fe}^{2+}$ and $\mathrm{Fe}^{3+}$ resulted in significantly enhanced activity only if the iron species were introduced to the surface of $\mathrm{Au} / \mathrm{SiO}_{2}$. Further investigation indicated that the $\mathrm{Au}-\mathrm{Fe}$ interfaces were well generated in this sample, mainly due to the selective accumulation of $\mathrm{Fe}^{3+}$ hydrolysis species induced by the heterogeneous nucleation and electrostatic adsorption. Therefore, electrostatic adsorption can be applied as an efficient method to produce small and dispersed Au NPs on vivid unreducible supports, providing the possibility of efficient gold catalysts on unreducible supports for many heterogeneous reactions.

\subsection{Colloid immobilization}

The colloid immobilization method is a method for depositing nanoparticles by immobilizing the related colloid solution of metal nanoparticles with subsequent in situ or ex-situ reduction processes, which is also considered as a sol-gel strategy to a certain degree. Bianchi and coworkers [104] reported the synthesis of $\mathrm{Au}-\mathrm{Pd}$ catalyst by successive reductions of $\mathrm{Au}$ in the presence of Pd metal sol, which was subsequently immobilized on a carbon support. $\mathrm{NaBH}_{4}$ was performed as a reducer for both metals in the presence of PVA as a protective agent. It was also confirmed that adding sequences of chemical agents played a great role in the formation of bimetallic nanoparticles. The bimetallic nanoparticles with an average diameter of approximately $3.5 \mathrm{~nm}$ displayed an alloy structure with surface segregated Pd atoms, if Pd NPs were generated on activated carbon first. If the gold precursor was reduced preliminarily by 
$\mathrm{NaBH}_{4}$ on the surface of the activated carbon and palladium was generated subsequently by $\mathrm{H}_{2}$, growth of $\mathrm{Pd}$ on $\mathrm{Au}$ without Pd segregation could be obtained due to the slow reduction rate and well diffusion [105].

The advantage of the colloid strategy in producing Au NPs is that the sizes and shapes can be designed and maintained if no harsh post-treatment is carried out. It can be used as a fundamental process to understand the size effect, support effect, the function of surface active sites, and roles of specific defects for target reactions [106,107]. Zhong et al. [108] investigated the PVP stabilized Au NPs supported by silica (Fig. 10). It was found that Au NPs connecting with carboxylic groups of PVP were immobilized on the surface of the silica with better interaction, and the PVP was subsequently eliminated by UV/ozone treatment. Characterization suggested that the sizes, shapes, and interplanar distances were maintained after UV/ozone treatment for $12 \mathrm{~h}$ reaction. The chemical valence of the gold species changed and was ascribed to the electron donation of $\mathrm{C}=\mathrm{O}$ from the PVP component. The impacts of stabilizer on the catalytic performances also depended on the target reactions. However, the presence of a surfactant such as polyvinyl alcohol (PVA), polyvinylpyrrolidone (PVP), or cetyltrimethylammonium bromide (CTAB) caused the contamination of residues that might sterically lead to the coverage of the catalytic sites, change the electronic state, and hinder the interaction between gold and support [109-112]. Although they may be washed and removed after gold loading with chemical solvents such as $\mathrm{KMnO}_{4}$, the Au NPs may be aggregated and secondary contamination could be induced [112-114].

The most concerning risk of the colloid immobilization method is its potential limitations in reactions due to the specific reagents used for colloidal Au NPs. Quinet et al. [115] reported that the $\mathrm{Au} / \mathrm{Al}_{2} \mathrm{O}_{3}$ by the colloid deposition method only displayed inferior performance for $\mathrm{CO}$ oxidation in the presence of $\mathrm{H}_{2}$, independent of its smaller particles (approximately $4 \mathrm{~nm}$ ). They announced that the catalytic performance was irrelevant to the size effect, but the passivation effect from the stabilizer of Au NPs was not discussed.

Parmentier et al. [116] deposited Au NPs on the surface of high-surface-area activated carbon via colloid immobilization or impregnation with an aqua regia solution of gold. However, the Au NPs were still poisoned and deactivated by the formed organic compounds and intermediates unless a base promoter

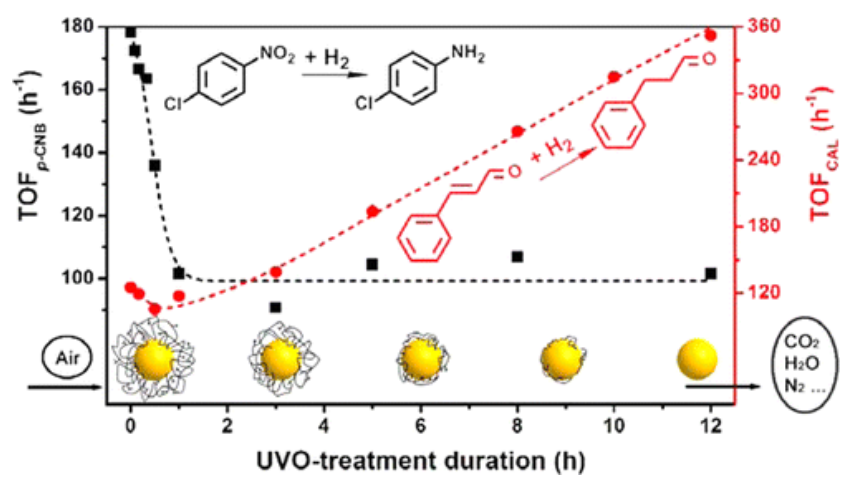

Fig. 10. TOF based on p-chloronitrobenzene (p-CNB) and cinnamaldehyde (CAL) as a function of UVO-treatment duration [108]. was used [117]. It was suggested that the presence of polyvinyl alcohol (PVA) hindered the exposure of gold active sites during the reaction, which led to the unpromising performance for the homo-coupling of phenylboronic acid. It was also confirmed that atomically dispersed gold could be formed on the $\mathrm{Au} / \mathrm{C}$ catalyst prepared using aqua regia, which, however, tended to be reduced to form large particles during the reaction. The thermal stability of the carbon materials supported Au NPs is still a considerable challenge in the research work. Our previous work also found that fine and uniformly dispersed Au NPs could be immobilized on the surface of CNTs after preliminary ozone functionalization [28,118], where the abundant surface oxygenated groups of support facilitated the anchoring of $\mathrm{Au}$ NPs (Fig. 11). The Au/oCNT was used for oxidative coupling of benzylamine, and the imine selectivity higher than $99 \%$ with $56 \%$ amide conversion was achieved using an $\mathrm{O}_{2}$ balloon in the absence of either base or solvent. However, the stability of supported Au NPs requires further enhancement.

\subsection{Pre/post-treatment}

In order to activate the catalysts, pre and/or post-treatments are carried out under different conditions. The morphology, chemical state of active sites, and the synergy between gold and support can be changed based on different gas atmospheres and treatment conditions. Kraszkiewicz et al. [98] synthesized $\mathrm{Au}$ NPs stabilized by mesoporous SBA-15 using $\left[\mathrm{Au}(\mathrm{en})_{2}\right] \mathrm{Cl}_{3}$ complex as a precursor. It was suggested that gold clusters could be preliminarily stabilized by $\mathrm{H}_{2}$ reduction, and severe aggregation of Au NPs would be avoided during the further calcination process in oxygen up to $600{ }^{\circ} \mathrm{C}$. The samples pre-treated under $400{ }^{\circ} \mathrm{C}$ in $\mathrm{H}_{2}$ and then calcined in oxygen at $300{ }^{\circ} \mathrm{C}$ displayed much better catalytic performance with $100 \%$ CO conversion at only $25{ }^{\circ} \mathrm{C}$. Especially for unreducible-material-supported Au NPs with metal oxide doping, pre-treatment can change the samples into a more activated state, which could further contribute to stabilizing and promoting their catalytic performances. Liao et al. [119] investigated the pre-treatment effect for copper oxide doped Au NPs.

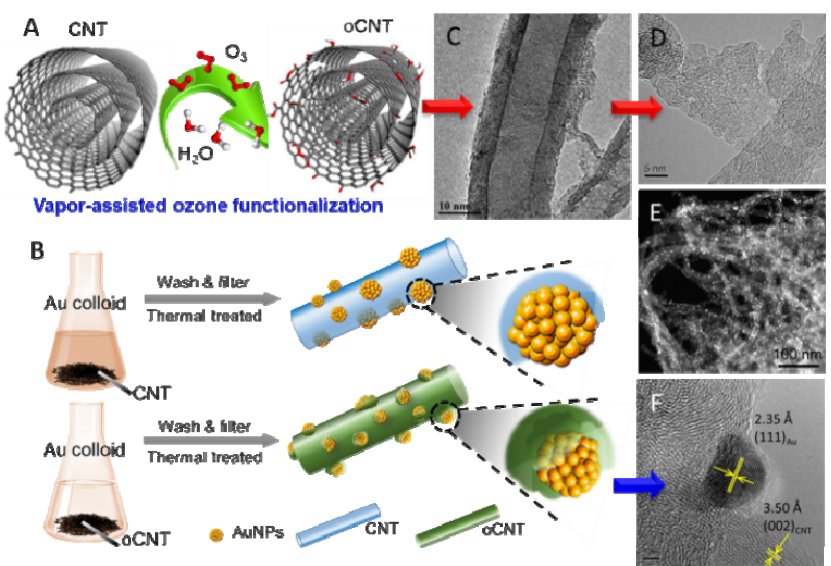

Fig. 11. Schematic of vapor-assisted ozone functionalization of CNT (A) and schematic of colloidal Au NPs deposited on CNT and oCNT (B), functionalized oCNT under mild (C) and harsh (D) conditions, STEM and HR-TEM images of Au/oCNT after calcination (E,F) $[28,118]$. 
The chemical state of copper was found to greatly vary as the treatment condition changed. Calcination under air led to the formation of oxidized copper and segregation of $\mathrm{Cu}$ to form the $\mathrm{CuO}$-rich surface, where carbonate-like species were easily formed during the PROX reaction. Pre-treatment by reduction resulted in the generation of $\mathrm{Au}-\mathrm{Cu}$ alloy and metallic copper with much better performance and stability irrespective of the atomic ratio between $\mathrm{Cu}$ and $\mathrm{Au}$.

Other synthesis methods and assisted treatments can also be applied during the preparation of unreducible-material-supported Au NPs, such as the micro-wave and ultrasonic assisted procedures. Wittanadecha et al. [120] synthesized the carbon-supported Au NPs by both ultrasonic assistance and micro-wave treatment. It was suggested that compared with the ultrasonic-assisted synthesis, the micro-wave treatment was proven to be more beneficial for enhancing the catalytic performance for the acetylene hydrochlorination. It was also confirmed that although the micro-wave treatment could promote the dispersion of Au NPs with $1 \mathrm{wt} \%$ loading, they aggregated if the gold loading continuously increased. In addition, the initial activity was distinctive and affected directly by different assisted methods, which were confirmed to be non-conducive to long-term stability. The recent work of Haruta and colleagues also modified the deposition-precipitation method by the micro-wave assisted drying process [121]. In general, positively charged gold species ( $\left.\mathrm{Au}^{\mathrm{III}}\right)$ in gold precursor can be mainly reduced during the thermal drying process. In this work, $\mathrm{Au}^{\mathrm{III}}$ species were preserved by micro-wave assisted drying due to the fast and uniform heating process. The white line intensity in the XANES of $\mathrm{Au} / \mathrm{Al}_{2} \mathrm{O}_{3}$ dried by micro-wave assistance was nearly identical as that of the $\mathrm{Au}(\mathrm{OH})_{3}$ reference, suggesting a large amount of positively charged gold species in this sample. The remaining existence of $\mathrm{Au}^{3+}$ species also indicated the strong interaction formed between gold and the support, which in turn protected Au NPs from sintering during thermal reduction. The final particle sizes in the catalyst could be considerably reduced to $1.4 \mathrm{~nm}$ using alumina as support.

Plasma is a type of gas consisting of charged particles, which is one of the four fundamental states of matter besides the liquid, gas, and solid states. The advantage of using plasma is that the energy dissipated in the plasma is mostly used to accelerate the electrons, and not spent on heating the entire gas stream. The energetic electrons in the plasma are highly efficient in producing radicals and oxidizing agents. Among the plasma techniques, non-thermal plasma is usually related to low temperature, non-thermodynamic equilibrium, and low pressure, which is capable of resisting the destruction of structure and crystal forms [122-124]. In the catalysis field, the pre-treatment of a catalyst by non-thermal plasma is essential for changing the chemical property and micro-structure of catalyst. It in turn leads to the possible optimization of the metal-support interaction, surface dispersion, metal particle size, and the redox properties $[125,126]$. It has been demonstrated that the plasma technique acts as an efficient treatment for pre-treating or synthesizing novel and useful materials [127].

Suarez-Martinez et al. [128] deposited Au NPs onto the plasma treated CNT by the thermal evaporation method. The study was primarily focused on the defective surface of CNT caused by plasma for the deposition and dispersion of Au NPs. DFT calculations suggested that the gold diffusion barrier was distinctive on the plasma functionalized surface (Fig. 12). The barrier of Au on pristine CNT was calculated to be $0.1 \mathrm{eV}$ by the DFT method, corresponding to the moving speed of $2 \cdot 10^{11}$ hops/second of the isolated $\mathrm{Au}$ atoms on the graphitic surface at room temperature. The limit barrier was calculated as 0.51-0.61 eV for gold to depart the oxygenated vacancy and oxygenated divacancy defect sites, corresponding to the much-decreased moving speed of only $2 \times 10^{4}$ hops/sec. The plasma-treated CNT was able to capture the $\mathrm{Au}$ atoms for a longer time to reduce their mobility and acted as nucleation sites. On the other hand, oxygen plasma treatment was reported to graft $\mathrm{C}=\mathrm{O}$ and $\mathrm{C}-\mathrm{O}-\mathrm{C}$ functional groups at the CNTs surface as a result of processes such as $\mathrm{O}_{2}{ }^{+}$dissociation on vacancies created during the plasma treatment [129]. Therefore, the improved dispersion of Au clusters can be associated with the dispersed oxidized vacancies at the CNT surface. The combination of experimental and theoretical results suggested that the nucleation of gold occurred at defect sites, which can be easily caused by plasma treatment.

Our previous work also focused on the plasma treatment and its influence on $\mathrm{CoO}_{x}$ and promoted Au NPs supported on silica [130]. The powder of as-synthesized $\mathrm{Au} / \mathrm{CoO}_{x} / \mathrm{SiO}_{2}$ was thermally treated by oxygen plasma at $300{ }^{\circ} \mathrm{C}$ instead of calcination in the air. The plasma treatment could facilitate the dispersion of smaller Au NPs on the surface of silica. On the other hand, the microscopic structure was also greatly improved in terms of surface contact and mesoporous texture. In addition, the plasma treatment under an oxidative atmosphere also led to the generation of abundant oxygen-supply centers. The modification of both surface and chemical properties was responsible for the much-accelerated activity for low-temperature CO oxidation.

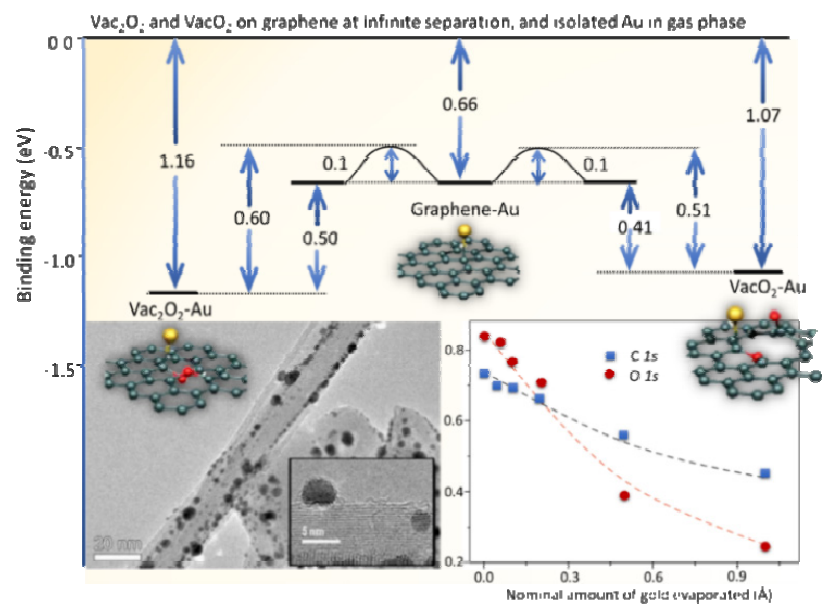

Fig. 12. (A) Plot showing the DFT calculated binding energies (in eV) and barriers for auto graphene, oxygenated divacancy $\left(\operatorname{Vac}_{2} \mathrm{O}_{2}\right)$, and oxygenated vacancy $\left(\mathrm{VacO}_{2}\right)$; (B) Au clusters formed on CNT surfaces after a nominal Au evaporation of $5 \AA$ pristine MWCNTs; (C) Variation of the $\mathrm{C} 1 \mathrm{~s}$ and $\mathrm{O} 1 \mathrm{~s}$ core levels peak intensity for increasing amounts of Au evaporated onto CNTs- the lines are a visual guide only [128]. 


\section{Modification of physical and chemical properties}

The catalytic activity of supported Au NPs can be effectively affected by the sizes, morphology, electronic states, formation and exposure of active sites, the interaction between gold and support/dopant, and the Au-metal oxide interfaces. Therefore, the modification of unreducible-material-supported gold catalysts induces great variations of the above properties and thus the catalytic performances for diverse reactions. Below, we aim at discussing the influences of promoting methods related to the physical and chemical properties of unreducible-material-supported Au NPs.

\subsection{Modification of chemical structure}

Modification of either the support or the entire catalyst leads to direct changes in the chemical structure, specifically depending on the detailed strategy and the nature of additional components. Transition metal elements such as $\mathrm{Cu}, \mathrm{Fe}, \mathrm{Ni}, \mathrm{Co}$, and $\mathrm{Zn}$, have been widely applied as dopants for Au NPs. Gamboa-Rosales et al. [131] found that the capacity to release lattice oxygen to oxidize $\mathrm{CO}$ could be highly increased in the $\mathrm{Au}-\mathrm{CuO} / \mathrm{CeO}_{2}$ compared to either $\mathrm{Au} / \mathrm{CeO}_{2}$ or $\mathrm{CuO} / \mathrm{CeO}_{2}$. It was also suggested that the surface ratio of gold and copper oxide to the support depended on the preparation method. Nikolaev and coworkers [132] studied the performances and synergistic effects of copper and cerium added to Au NPs supported on aluminum. The high efficiency of metal oxide doped gold catalysts versus pure metal catalysts with poor activity was ascribed to the synergistic effect between different metal oxides and gold. They also evidenced that the positively charged gold species and metal oxide species at the interfaces of Au-metal were responsible for the catalytic activity. We synthesized the non-porous silica-supported Au NPs of approximately 2-4 nm by the colloid immobilization method [27]. However, the supported Au NPs performed unsatisfactory catalytic activity for CO oxidation. The catalyst was further promoted by transition oxide including $\mathrm{CuO}, \mathrm{FeO}_{x}$, and $\mathrm{CoO}_{x}$ [21]. The contributions of metal to the CO reaction in regard to oxidative species of gold, silica, and dopants were identified, where metal oxides with different properties displayed distinctive evolution behaviors during the CO oxidation (Fig. 13). All the Au/SS5@M-C samples $(\mathrm{M}=\mathrm{Fe}, \mathrm{Co}$, or $\mathrm{Cu}$ ) displayed much better catalytic activity for CO oxidation compared to the Stöber silica-supported Au NPs. The CuO promoted Au/SS5@Cu-C sample displayed better CO conversion at lower temperatures, where $\mathrm{CuO}$ evolved during the CO oxidation and played the role of "glue" to anchor Au NPs. The $\mathrm{FeO}_{x}$ was also beneficial for fixing Au NPs on the surface of silica, which led to the encapsulation of the Au NPs by the $\mathrm{FeO}_{x}$ species. Cobalt oxide species were ready to form separate $\mathrm{CoO}_{x}$ particles around Au NPs, which partially limited the available $\mathrm{CoO}_{x}-\mathrm{Au}$ interfaces and caused the efficient $\mathrm{CO}$ oxidation.

Based on the investigations concerning precious metal doped gold catalysts, the precious metals including Ag, Pt, Pd, and $\mathrm{Ru}$ were applied as the dopants and compared with the bare gold catalysts. One of the most representative, the Pt doped gold catalyst, which is miscible with outstanding per- formances in different catalytic applications by forming AuPd alloys and limiting the segregation of single metals, was efficiently used for reactions including alcohol and polyol oxidation, direct production of $\mathrm{H}_{2} \mathrm{O}_{2}$ from $\mathrm{H}_{2}$ and $\mathrm{O}_{2}, \mathrm{C}-\mathrm{C}$ coupling and $\mathrm{CO}$ oxidation [133-136]. An earlier study suggested that the introduction of Pt could enhance the dispersion of Au NPs and the stability due to the fact that $\mathrm{Pt}_{50} \mathrm{Au}_{50}$ alloy was formed during the synthesis [137]. Moreover, it was implied that the interaction between the support and the nano-alloy greatly impacted the structural and chemical orders of the atoms, which induced the tunable active sites on alloys and were beneficial for the effective oxygen activation in reactions such as CO oxidation [138].

\subsection{Effect on electronic structure}

The additional metal oxide dopants may also change the pristine electronic structure of the gold catalyst due to charge transfer between active metal and support. The charge transfer occurs via the nanoscale interfaces between gold and support, which is important for the formation of metal-support interaction and the catalytic performance [139]. However, charge transfer could be hindered if unreducible materials were used as support. Fortunately, dopants can change the electronic structure and deliver the electrons.

Various publications provide evidence of electronic modification after doping processes. Doherty and coworkers [140] synthesized the AuPt particles supported on silica using polyacrylic (PPA) as a stabilizer, and suggested that the core-shell structure was restructured into the alloy after stabilizer decomposition. Furthermore, compared to the bare gold catalyst, the AuPt catalyst displayed distinctive reaction orders based on both $\mathrm{CO}$ and $\mathrm{O}_{2}$ as a function of the $\mathrm{Au} / \mathrm{Pt}$ ratio. Both the XPS and CO-FTIR results suggested the higher electron density of $\mathrm{Pt}$ in the AuPt system, which was indicative of the electron transfer from $\mathrm{Au}$ to Pt and accounted for the variation of the reaction orders and the synergistic effects. It was also demonstrated

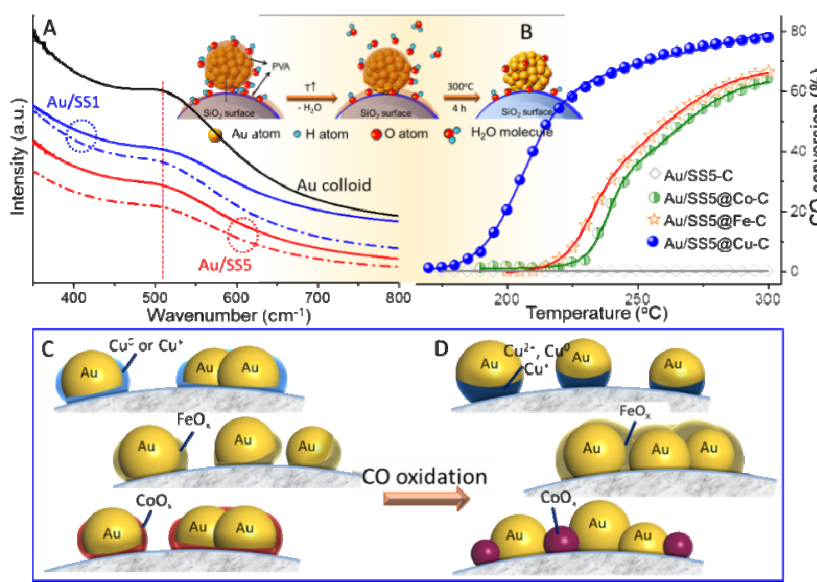

Fig. 13. (A) Uv-vis of initial Au colloid and supernatant Au colloid in the presence of SS1 and SS5 with different silica diameters; (B) CO conversion as a function of temperature over different gold catalysts; $(C, D)$ schematic description of the nanostructure variations of different $\mathrm{Au}$ catalysts during $\mathrm{CO}$ oxidation. The upper inset picture illustrates particle changes during thermal treatment $[21,27]$. 
that the addition of metal oxide could change the valence of gold species. Nikolaev et al. [132] used different metal oxides as dopants for gold catalysts. The $\mathrm{Au}^{\delta+}$ sites accelerated the adsorption of $\mathrm{CO}$ and stabilized the $\mathrm{O}$ atoms on the gold surface due to the emerging synergistic effect between gold and dopants. The electron density on the $\mathrm{Au}-\mathrm{Cu}$ alloy was claimed to be much higher than those of either pure gold or copper particles due to homogeneously mixed $\mathrm{Au}-\mathrm{Cu}$ atoms by the alloying effect $[141,142]$. In addition, the formed nanoparticles can effectively restrain the reverse transportation of the accumulated electrons [143].

Toshima and coworkers [144] synthesized crown-jewel-like Pd-Au nanocrystals by depositing Au atoms on pristine Pd NPs via the replacement reaction method. The above catalyst with a specific structure exhibited significantly enhanced activity for catalytic oxidation of glucose. The donation of an electron from $\mathrm{Pd}$ to $\mathrm{Au}$ atom was revealed by both the XPS result and DFT calculation, which caused the negatively charged density of gold and was announced to be responsible for the significantly promoted catalytic activity, as shown in Fig. 14.

Louis and his groups investigated the bimetallic Au-Pd catalysts for reactions, including CO oxidation, cyclohexene hydrogenation, and oxidation of 1,3-butadiene/propene [145-147]. It was confirmed that the electronic effect existed in the Pd assisted Au NPs, where charge transferred during treatment by different gases. Under $\mathrm{CO}$ atmosphere, Pd could be enriched on the surface of the catalyst, whilst it was barely exposed on the surface after $\mathrm{H}_{2}$ reduction. On the other hand, $\mathrm{CO}$ can be adsorbed on the surface of metallic $\mathrm{Au}$, and the non-metallic $\mathrm{Pd}$ due to its exposure in the air did not have any significance for $\mathrm{CO}$ adsorption. The electronic effect also induced the modification of nascent adsorption enthalpy $\left(\Delta H_{0}\right)$, as well as the resulting distinctive performances in oxidation and hydrogenation processes.

\subsection{Au-support interaction/synergy}

Gold-support interaction is considered as one of the most

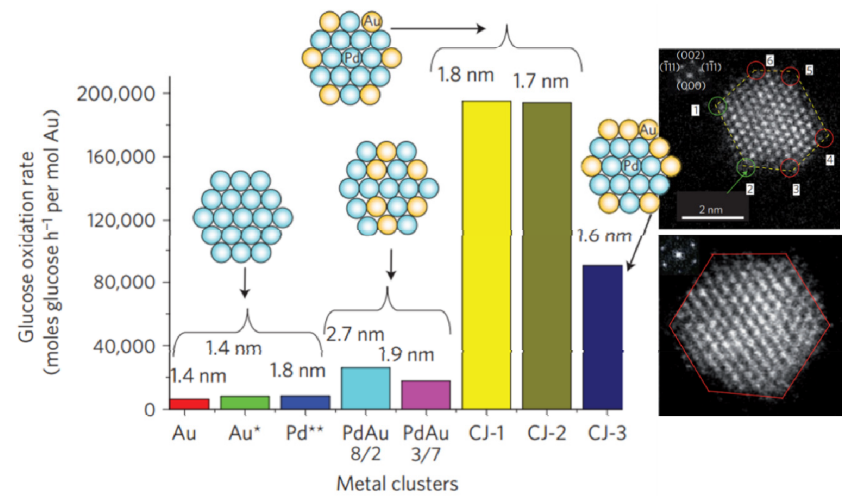

Fig. 14. Comparison of the catalytic activity of $\mathrm{CJ}-\mathrm{Au} / \mathrm{Pd}, \mathrm{Au}, \mathrm{Pd}$, and $\mathrm{Pd} / \mathrm{Au}$ alloy NCs for aerobic glucose oxidation [144]. Schematic insets and numbers shown at the top of each bar indicate the structural models and the average particle sizes, respectively, of the NCs; $\mathrm{Au}^{*}$, the activity was normalized by the number of surface $\mathrm{Au}$ atoms in NCs; $\mathrm{Pd}^{* *}$, the activity was normalized by the number of surface Pd atoms, the activity of 8290 moles glucose $\mathrm{h}^{-1}$ per mole surface $\mathrm{Pd}$. important factors for the catalytic activity of structure-sensitive reactions, such as $\mathrm{CO}$ oxidation and selective gas-phase oxidation of alcohols to aldehydes/ketones. However, the fundamental understanding of the real function of Au-support interaction with the camouflage of other factors such as the prominent size effect remains challenging. Controllable fabrication of catalysts with equal sizes provides a feasible method for these tasks.

The strong metal support interaction (SMSI) was suggested by Tauster et al. [148] for the first time to illustrate the suppressed adsorption of $\mathrm{H}_{2}$ and $\mathrm{CO}$ on titania supported group VIII metals after $\mathrm{H}_{2}$ reduction. The term has been expanded to many other metal and metal oxides. The SMSI is also of great importance for supported Au NPs, which is significant for stabilizing Au NPs with enhanced catalytic performances. However, it was previously considered that gold could not manifest the SMSI due to the low work function and surface energy [149], especially those supported on unreducible supports such as nano-carbon materials, silica, and non-oxides. Nevertheless, the concept has been evolving along with the rapidly developed investigations on nano-gold materials during the past ten years [150,151]. Wang et al. [152] reported for the first time their discovery of the SMSI phenomenon based on $\mathrm{Al}_{2} \mathrm{O}_{3}$ supported $\mathrm{Au}$ NPs by revealing the full encapsulation of gold by alumina, which resulted in anti-sintering stability until $900{ }^{\circ} \mathrm{C}$. They also provide the conjecture by high-resolution TEM that the gold-alumina interfaces constructed by $\mathrm{Au}$ (111) and $\mathrm{Al}_{2} \mathrm{O}_{3}$ $(22 \overline{2})$ facets, which were ready to epitaxially transform into $\mathrm{Au}$ (002) and $\mathrm{Al}_{2} \mathrm{O}_{3}$ (220) facets due to coherent lattice spacing and interface boundaries, as well as the smaller interfacial energy during thermal treatment at $900{ }^{\circ} \mathrm{C}$.

The recent work of Tang et al. [68] focused on the interaction between the support and gold based on exceptional supports such as hydroxyapatite, which was considered as unreducible support or "inert" support. However, high temperature $\left(800^{\circ} \mathrm{C}\right)$ calcination led to the total encapsulation of the $\mathrm{Au}$ NPs by the hydroxyapatite support in their work, which resulted from the strong Au-support interaction. The Au NPs were maintained without further aggregation due to the outside layer, which was unsuitable for CO oxidation due to the covering of the gold sites. Furthermore, the authors tried to adjust the encapsulation degree of $\mathrm{Au}$ NPs by introducing $\mathrm{TiO}_{2}$ as a dopant [67]. It was found out that Au NPs were preferentially located on the interfaces of hydroxyapatite and $\mathrm{TiO}_{2}$. The small $\mathrm{Au}$ NPs were partially encapsulated by hydroxyapatite while connecting with $\mathrm{TiO}_{2}$, hindering the further sintering even under thermal treatment at $800{ }^{\circ} \mathrm{C}$. Although, the partial encapsulation of $\mathrm{Au}$ NPs also ensured the necessary exposure of gold active sites for $\mathrm{CO}$ oxidation, which resulted in excellent reactivity and stability. This work provided a new insight into the development of unreducible supports and the interaction between Au-unreducible supports.

Pizzutilo et al. [153] applied harsh electrochemical conditions to cause the degradation of Au-Pd metallic particles using carbon as support. By controlling the dissolution onset potentials (ADP), the atomic environment of Au-Pd bimetallic particles could be finely controlled. The dissolution behaviors of Pd 

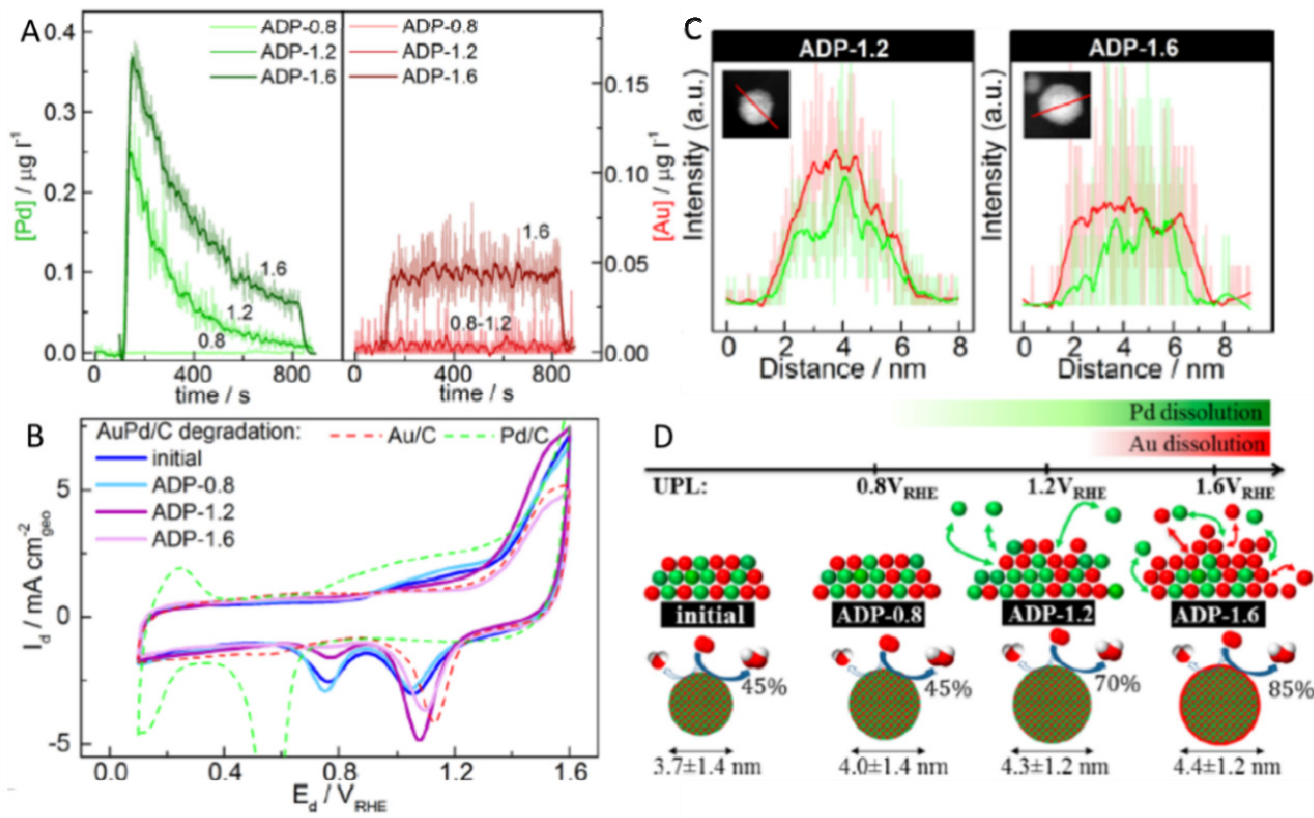

Fig. 15. (A) Online Pd and Au dissolution profiles recorded with AuPd/C by the SFC/ICP-MS technique during degradation cycle voltammograms; (B) Initial AuPd/C CV (0.1-1.6 VRHE) in Ar-purged 0.1 $\mathrm{MHClO}_{4}$ and after degradation protocols; (C) Catalyst EDS line scan after degradation; (D) Representative evolution of the surface composition and the $\mathrm{H}_{2} \mathrm{O}_{2}$ selectivity (\%) during the ADPs [153].

and Au were captured by the online Pd and Au dissolution profiles using the SFC/ICP-MS during degradation (Fig. 15(A)), under different ADPs. Two distinct peaks corresponding to the reduction of $\mathrm{Pd}$ oxide and $\mathrm{Au}$ oxide were observed during the reverse scan (Fig. 15(B)). It was also confirmed that the significant surface composition evolution considerably modified the electrochemical behavior, leading to a reasonable activity for the direct $\mathrm{H}_{2} \mathrm{O}_{2}$ synthesis (Fig. 15).

\subsection{Size effect and modification of particle morphology}

Boronat and Corma [154] conducted DFT calculations based on oxygen activation on the surface of $\mathrm{Au} / \mathrm{TiO}_{2}$. It was suggested that the bridge-bridge conformers of oxygen adsorbed on $\mathrm{Au}$ had the lowest activation barrier for the dissociation of molecular oxygen, which was only stable on the Au (100) facets. In particular, the morphology and particle size should be one of the essential factors for the dissociation of oxygen in gold catalysts.

On the one hand, one of the modification targets of unreducible-material-supported Au NPs is to get small dispersed $\mathrm{Au}$ NPs with good thermal stability. For reactions such as CO oxidation and VOC oxidation based on Au NPs, the L-H mechanism is more likely to occur on the surface of the catalyst. $\mathrm{Au}$ NPs with smaller sizes offer more kink and corner sites, which could be the active sites to forcefully adsorb the reactants, dissociate and activate oxygen species, and ensure outstanding performances for many structure-sensitive reactions [155-157].

The size effect has always been considered as one of the essential factors for catalytic activities by many researchers. It was suggested that the sizes of Au NPs were also responsible for the catalytic activity for oxidation of short chain alkanes, such as methane. Grisel et al. [158] investigated the activity of $\mathrm{Au} / \mathrm{Al}_{2} \mathrm{O}_{3}$ with metal oxide promotion, including the $\mathrm{MnO}_{x}$, $\mathrm{FeO}_{x}, \mathrm{CoO}_{x}, \mathrm{NiO}$, and $\mathrm{CuO}$, for methane combustion. The results suggested that small Au NPs were preferential for the conversion of methane. In heterogeneous catalytic systems, there are two mechanisms associated with metal particle sintering: 0stwald ripening and particle migration. Using thermal synthesis methods, there have been some interesting reports aimed at producing doped gold catalysts with special structure for more defect sites and exposed active species with advanced chemical and physical properties. Wang and coworkers [159] synthesized Au NPs with different sizes supported on mesoporous carbon using a two-step carbonization method (Fig. 16). The FT-EXAFS and XANES results indicated the loss of metallic feature in the order of $100 \mathrm{~nm}-\mathrm{Au}-\mathrm{C}<9 \mathrm{~nm}-\mathrm{Au}-\mathrm{C}<3 \mathrm{~nm}-\mathrm{Au}-\mathrm{C}$. Considering the less-interacting effect between gold and carbon, the distinctive electric modification should only result from the reduction of particle sizes. It was also confirmed that the smaller Au NPs (3 nm) induced a much-shortened distance between $\mathrm{Au}-\mathrm{Au}$, which favored enhanced $\mathrm{d}$-d interactions, narrowed the d-band, and lowered the energy of the d-orbitals.

However, some researchers disagree with the "exaggerated" impact of the size effect. Solsona et al. [160] investigated the $\mathrm{Au} / \mathrm{Ni}-\mathrm{Ce}-\mathrm{O}$ system for $\mathrm{CO}$ oxidation and reported that the larger surface area of the catalyst instead of the smaller sizes of gold should be more responsible for the exposure of active sites. In this case, the smaller gold particles in $\mathrm{Au} / \mathrm{CeO}_{2}(2-10$ $\mathrm{nm}$ ) only displayed inferior catalytic performance compared with the $\mathrm{Au} / \mathrm{Ni}-\mathrm{Ce}-\mathrm{O}$ with bigger particles (5-15 nm) and much larger surface area. Gasior et al. [161] explored the gold catalysts supported on distinctive supports, including magnesia, 

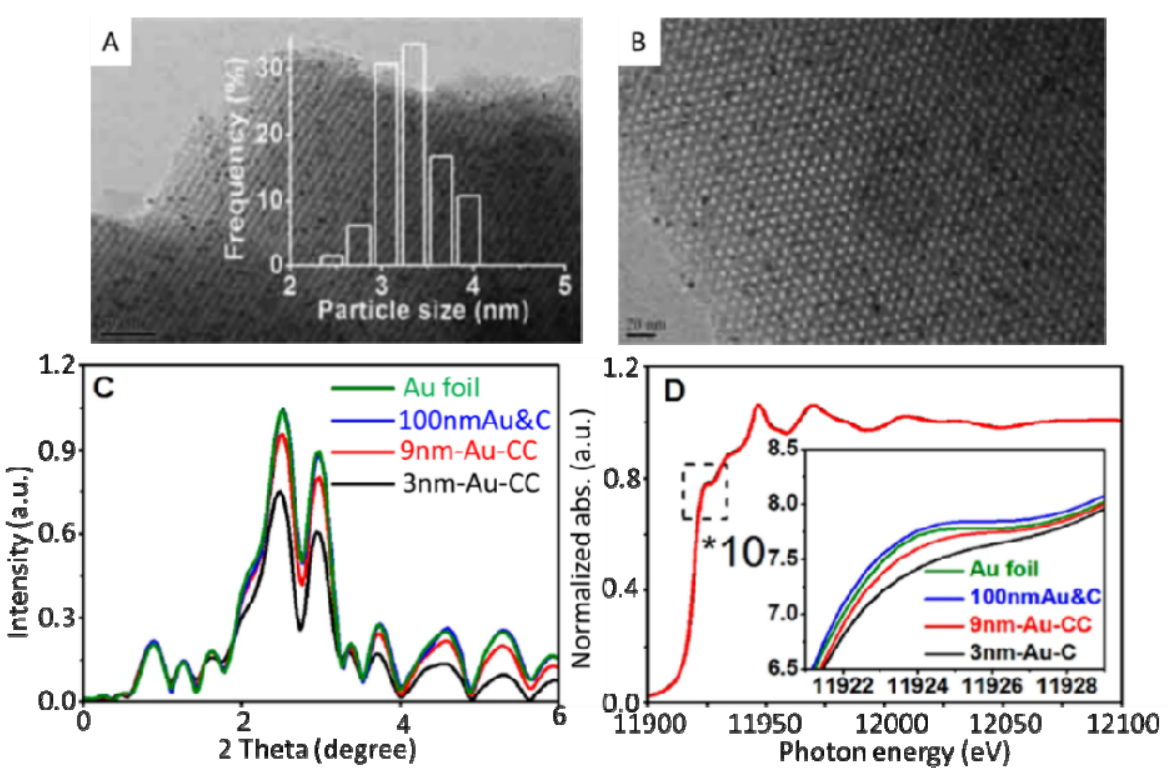

Fig. 16. (A,B) TEM images of the $3 \mathrm{~nm}-\mathrm{Au}-\mathrm{C}$ observed along the (110) and the (001) directions; FT-EXAFS (C) and XANES (D) spectra for (a) 3.4 and (b) $8.9 \mathrm{~nm}$ gold particles on carbon [159].

silica, titania, iron oxide, and ceria for propane oxidation and did not report any observable size effect. A review by Kipnis et al. [162] also opposed the work concerning the relationship only between average size and catalytic performance. They even denounced the size effect in several research works and ascribed the possible changes to the variation of gold contents. The size effect is sensitive and should be fully revealed without the complications of, for example, the support effect and $\mathrm{Au}$-support interaction. Besides, the size effect is more likely to occur on the unreducible supports such as silica, alumina or other comparative supports due to the futile $\mathrm{O}_{2}$ activation ability of unreducible support. Moreover, the size effect should be more apparent and precisely expressed based on both average size and size distribution.

Recently, a single atom catalyst (SAC) has been reported by Zhang et al. for the first time since 2011 based on platinum, where all active metal species are present in the forms of isolated single atoms and stabilized by the support or promoter [163]. SACs can be viewed as an extreme case considering the "size" of Au species, and they have been since considered as a promising candidate for all kinds of heterogeneous reactions [164,165]. Au-based SACs have also been synthesized and reported to be efficient, especially for CO oxidation. Importantly, compared with other precious metal such as $\mathrm{Pt}, \mathrm{Ru}$, and $\mathrm{Pd}$, it is difficult to atomically disperse $\mathrm{Au}$ on a support, mainly due to the relatively high electronegativity and ionization potential of $\mathrm{Au}$. It was successfully deposited on mostly reducible supports, such as $\mathrm{FeO}_{x}, \mathrm{CeO}_{2}$, and $\mathrm{ZnZrO}_{4}$ [166-168]. Only several reports implied the successful deposition of atomic Au on the unreducible supports such as multi-wall carbon nanotubes (MWCNTs), zeolites, and mesoporous silica [42,169,170]. However, huge opportunities and challenges co-exist regarding the use of $\mathrm{Au}$ SACs for the heterogeneous reaction.

Furthermore, in addition to the particle sizes, the morphology of particles and structures of catalysts can also be control- lably modified. Au NPs on unreducible supports can be manufactured as nanospheres, triangles, and nanorods [171,172]. Nanoporous gold is a promising material whose remarkable catalytic performances and very good thermal stability for prolonged test runs were reported [173]. Wittstock et al. [174] created porous $\mathrm{Au}$ materials with a super high surface area, which was synthesized by leaching Ag from gold-silver alloys. The porous Au catalyst with a stable structure was used to catalyze the partial oxidative coupling of methanol with a high yield of methyl formate (above 97\%). It was inferred that oxygen could be easily activated by the surface of gold although the selective surface chemistry of Au may be modified, and the overall catalytic properties of nanoporous Au are in agreement with those on $\mathrm{Au}$ single crystals.

The morphologies of supported Au NPs can be formed differently according to the Au-support interaction and valence of gold species. For gold supported on titanium oxide, positive charges are likely to be generated on the surface of $\mathrm{TiO}_{2}$. The interface between gold and $\mathrm{TiO}_{2}$ is maximized to force the $\mathrm{Au}$ NPs shaped as half-spheroidicity. For Au NPs supported on metal oxide such as $\mathrm{MgO}$ and $\mathrm{Al}_{2} \mathrm{O}_{3}, \mathrm{Au}^{+}$and $\mathrm{Au}^{\delta+}$ may form on the surface of supports, and Au NPs contacting with the surface exist in the form of hemispheres. However, for gold supported on carriers such as carbon and silica, $\mathrm{Au}^{0} \mathrm{can}$ be formed and only few interface sites are formed on the contacting surface.

The gold nanoparticle will be erected on the support in a form of a regular separated particle.

Introducing additional metal oxide or surface functionalization will also change the nanostructure of the supported nanoparticles on the basis of different preparation methodologies and pre-treatments. Comparing with the pure gold catalysts, the doping composition may modify the nanostructure of the catalyst in general, according to the ratio between gold and dopant, the synthesis methodology, and the pre-treatment, which can be reflected in four typical cases: Segregated nano- 
particles with shared interfaces; uniform or randomly mixed bimetal alloy; and core-shell structures. The most commonly reported Au NPs after doping includes the core-shell structure (either regular core-shell or metal oxide partially encapsulated gold structure), randomly arranged alloy structure, and dumbbell structure $[175,176]$.

La Parola et al. [177] synthesized Au-Pt supported on silica using MPTES as a stabilizer within different aging time. It was found that the addition of Pt induced exact distinctive growth of nanoparticles unlike the bare Au or Pt NPs, which was evidenced to be a core-shell configuration. Remarkably, the Pt@Au was formed at the very beginning of the aging progress, which changed into the Au@Pt configuration after long-term aging. Such a phenomenon was reported useful for controllable synthesis of Au-Pt core-shell structure with tunable catalytic activity for target products. It is of great interest to control the synthesis of AuPt catalysts with distinctive nanostructures, either alloy or core-shell structure, following different procedures. Wu et al. [178] also synthesized the icosahedral gold-platinum nanocrystals encapsulated into hollow silica spheres. The shape-controlled nanocrystals were prepared by a hydrothermal method without capping agents, which possessed outstanding stability and excellent activity for the Ullmann reactions. Recent work concerning the AuPt bimetallic particles confirmed the importance of structure tailoring, which directly induced the modifications of the geometric and electronic properties [179]. The $\mathrm{Pt}_{4} \mathrm{Au}_{96}$ sample with particularly low Pt content displayed unprecedented catalytic performance for the oxidation of formic acid with the current density of $3.77 \mathrm{~A} \cdot \mathrm{mg}_{\mathrm{Pt}^{-1}}$. Both the experimental and theoretical results confirmed the existence of $\mathrm{Au}$ atoms surrounded by densely packed single-atom Pt surface sites. The tailored structure and alloy-bonding ability of the catalysts directly led to the superior performance and product selectivity (Fig. 17). The Au-Pd core-shell structure or nano-alloy could be formed by different methods with Pd deposited at the specific sites or the surface of the Au seed $[105,180]$.

In our recent work, it was found that ordered transformation of the metal precursors in $\mathrm{Au}-\mathrm{CuO}_{x}$ bimetallic samples led to direct influences on their catalytic performances during CO oxidation, as displayed in Fig. 18 [181]. The different adding sequences of copper and gold precursors caused the surface configuration and rearrangement during thermal treatment. The as-formed $\mathrm{CuO}^{*} / \mathrm{Au}$ with $\mathrm{Au}$ NPs partially encapsulated by $\mathrm{CuO}_{x}$ fractions and $\mathrm{Au} @ \mathrm{CuO}$ samples with the core-shell structure exhibited much accelerated CO conversion at a lower temperature. Rough surfaces constructed by unsaturated gold step sites were easily formed in $\mathrm{CuO}^{*} / \mathrm{Au}$, which was shown to be responsible for the accelerated catalytic behavior. $\mathrm{An} \mathrm{Au}-\mathrm{Cu}$ alloy structure could also be constructed by the appropriately tuned method. However, the synergistic interaction between $\mathrm{Au}-\mathrm{CuO}_{x}$ was proved to be too strong and accordingly, suppressed the activation of CO molecules [182]. Dynamic adsorption equilibrium could be formed between the structural evolution and the chemical behavior of the $\mathrm{Au}-\mathrm{Cu}$ alloy structure [182]. The interfaces and synergistic interaction between $\mathrm{Au}$ and additional copper species were forged in all the three samples, however, their adsorption/activation abilities during CO a

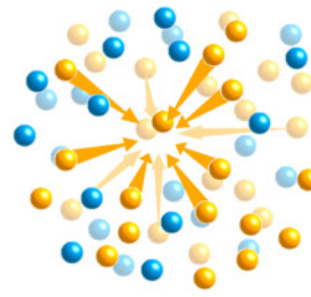

Au nucleation

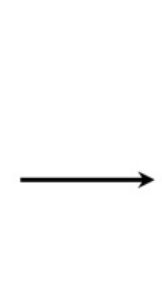

b

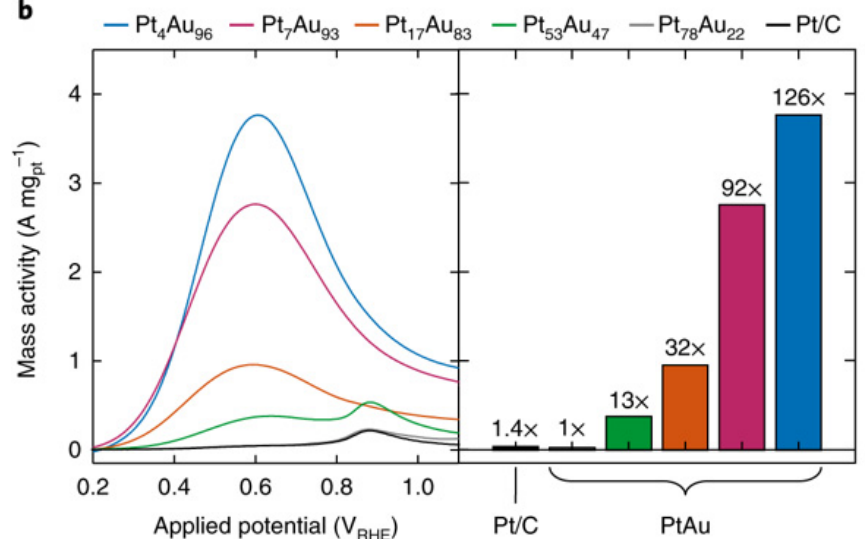

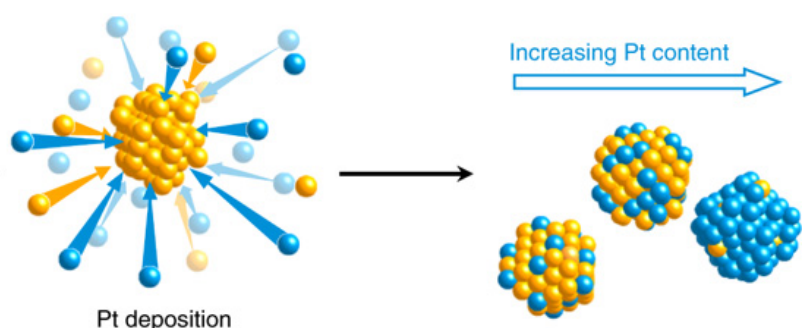

C

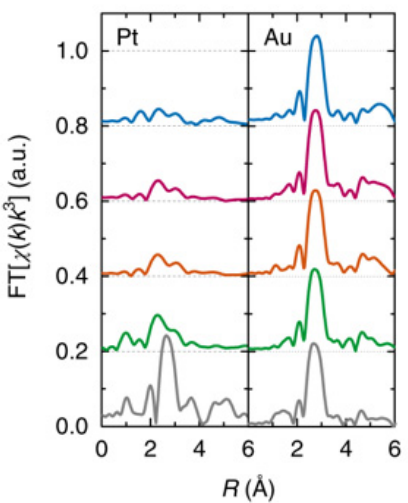

Fig. 17. (a) Illustration of the nanoparticle formation via the reduction of solvated ions; (b) Pt mass-normalized anodic sweeps obtained from PtAu nanoparticle catalysts in an electrolyte that contained $0.1 \mathrm{M}$ concentrations of both $\mathrm{HClO}_{4}$ and $\mathrm{HCOOH}$, with the peak currents graphed for comparison (left); (c) The plotted FT-EXAFS spectra obtained from Pt and Au L3-edge absorption spectra of PtAu NPs illustrate the drastic under the coordination of Pt atoms in low-Pt-content samples [179]. 


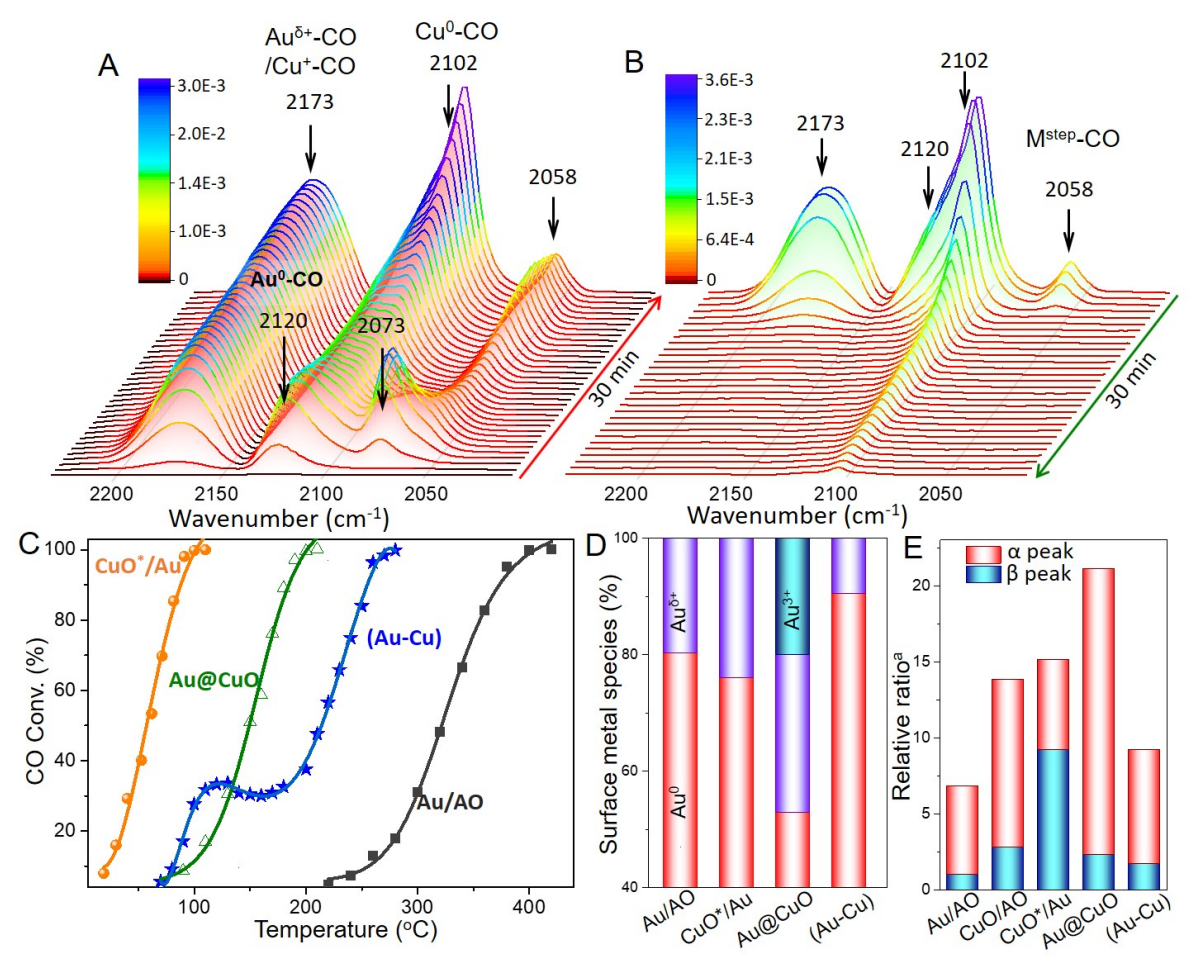

Fig. 18. (A, B) In situ DRIFT spectra of $\mathrm{CuO} * / \mathrm{Au}$ sample during $\mathrm{CO}$ adsorption and subsequent desorption in $\mathrm{He}$ at $25^{\circ} \mathrm{C}$; (C) $\mathrm{CO}$ conversion as a function of temperature by different catalysts; (D) The surface composition of Au species revealed by XPS spectra; (E) The relative ratio of $\mathrm{CO}_{2}$ desorption peaks at 100 and $300^{\circ} \mathrm{C}$ revealed by CO-TPD [181,182].

oxidation were distinctive. Both the in situ DRIFT spectra and the HR-STEM suggested that the different exposed low-coordinated gold step sites were formed during the nucleation process and resulted in the intrinsically formed defected rough surface (Figs. 18(A) and (B)). Although both the gold and copper active sites could activate and transform $\mathrm{CO}$ molecules, the exposed Au steps sites were responsible for the faster reaction rate. The surface morphology of nanoparticles in the nanoscale was fundamentally manipulated by the formation of surface active sites and the interfaces (Figs. 18(C)-(E)).

\subsection{Formation and particularity of Au-promoter/support interfaces}

The formation of the interface between $\mathrm{Au}$ and reducible support or the promoter (additional metal oxide) is another direct result induced by the promotion strategy for gold catalysts supported by unreducible support. In the related research work, the interfaces between gold and support/promoter are viewed as an important battle field during the reactions, which are essential for the oxygen supply, adsorption and activation of reactant, donating appropriate acid sites, as well as modifying the reaction pathway by forming significant reaction intermediates.

In an early work, Guczi et al. [183] deposited a 5-10 nm $\mathrm{FeO}_{x}$ layer on the surface of $\mathrm{Au} / \mathrm{SiO}_{2} / \mathrm{Si}(111)$ by a pulsed laser technique. It was confirmed that the active sites for CO oxidation were located on the $\mathrm{FeO}_{x}$ overlayer with $\mathrm{Au}$ underneath. The size-dependent electronic effect was reported due to the existence of $\mathrm{FeO}_{x} / \mathrm{Au}$ interfaces. Ji et al. [184] synthesized $\mathrm{Au}$ NPs supported on $\mathrm{SiO}_{2}$ modified with several amounts of titania. The results suggested that $\mathrm{Au} / \mathrm{Ti}$ dual interface sites were formed in the catalyst, and the interfacial Ti sites served as Lewis acids to capture $\mathrm{OOH}^{*}$ species. Silica with Brønsted acid sites may promote the $\mathrm{OOH}^{*}$ spillover. It further enhanced the probability of $\mathrm{OOH}^{*}$ transferring to the neighboring Ti sites and hindered the $\mathrm{OOH}^{*}$ decomposition to $\mathrm{O}^{*}$ on the Au surface. As a result, the further oxidation to propionic acid was suppressed and selectivity of PO was enhanced.

For some oxidation reactions, the newly formed interfaces also changed the oxygen supply ability of the entire catalysts during oxidation reactions. It is well known that the essential problem of the unreducible-material-supported Au NPs is the insufficient supplementation of oxygen species by unreducible supports. Accordingly, the activation and dissociation of oxygen species have become the rate-determining step for the catalytic performance of gold on unreducible supports. One of the starting points to the introduction of metal oxide is to enhance the oxygen supplying ability by only loading a relatively small amount of metal oxide. The additional metal oxide helps to fix gold species and forces a new interaction or synergy with gold, and lowers the expenses caused by a pure metal oxide base. Furthermore, the dopants of supported Au NPs may also contribute to transporting active oxygen species and charge transfer. The formation of gold-secondary metal bimetallic particles on unreducible support can be responsible for the enhancement of catalytic activity as oxygen molecules can be adsorbed and dissociated at the peripheral regions of the interfacial sur- 
faces between gold and species $[185,186]$.

\subsection{Presence of water/hydroxyl species}

The responsibility and influences of water/hydroxyl species are always considered and studied during reactions catalyzed by gold. However, such a seemingly simple question is complex, and consensus has not been reached even for the CO oxidation process [187]. It was previously reported that the presence of water or hydroxyl species can harm the catalytic stability of gold and easily lead to the deactivation of supported Au NPs. However, research results also indicated that a small amount of water in the feed stream enhanced the catalytic activity up to several orders of magnitude. In recent research studies, water/hydroxyl species either from the surface of the support or the reaction conditions were reported to participate in the reaction, help to decompose the reaction intermediate, and play a key role in the activation of reactants and the catalytic performance. Does water enhance the reaction by promoting the decomposition of surface intermediates or by assisting the activation of reactants? This is an intrinsic problem essential for understanding the mechanism of many reactions in gold catalysis. Zope and coworkers [188] suggested that the interfaces between gold and water were responsible for creating the reaction environment for better catalytic performance. They investigated the gold catalyst for alcohol oxidation in an aqueous solution at a high $\mathrm{pH}$ value combining both experimental and DFT results. The labeling experiments using ${ }^{18} \mathrm{O}_{2}$ and $\mathrm{H}_{2}{ }^{18} \mathrm{O}$ suggested that oxygen atoms in hydroxide species rather than molecular oxygen participated in the reaction of alcohol oxidation. On the other hand, the hydroxide species could be regenerated by molecular oxygen via the catalytic decomposition of a peroxide intermediate. Both solution-mediated and metal-catalyzed elementary steps were confirmed to be the predominant reaction path during the oxidation of alcohol at high $\mathrm{pH}$ value.

Saavedra et al. [189] also studied the influence of water during CO oxidation by combining kinetics study and infrared spectroscopy. It was confirmed that the reaction activation barrier was lowered after water presence by enabling $-\mathrm{OOH}$ groups to form from adsorbed oxygen. The as-formed - $\mathrm{OOH}$ species subsequently reacted with the CO molecules. Therein, the oxide support and its interface contributed to the activation of the water species, whilst gold active sites were responsible for the reaction steps involving activation of $\mathrm{CO}$, as illustrated in Fig. 19. For unreducible supports, the question is whether different cases occurred? In the later work of Saavedra based on a comparative study of $\mathrm{Au} / \mathrm{Al}_{2} \mathrm{O}_{3}$ and $\mathrm{Au} / \mathrm{TiO}_{2}$ for $\mathrm{CO}$ oxidation in the presence of $\mathrm{H}_{2} \mathrm{O}$, it was suggested that the reaction mechanisms were identical [190]. The amount of water induced in the reaction was revealed to be essential to the number of available active sites but had no significant effect on the intrinsic rate constants. The reaction process was fastest when the surface of the support was completely covered with water. The only difference in performance caused by the support was the number of active sites and their sensitivity to carbonate poisoning, where alumina seemed to be more sensitive to the water species. Water plays a key role in a number of other reactions catalyzed by gold catalysts [191]. The investigation by Saavedra et al. may provide possible resolutions to many unanswered questions in gold catalysis concerning the key role of water/hydroxyl species.

\section{Conclusion and perspectives}

During the past several decades, nano-gold has exhibited its superiority for heterogeneous reactions with both high reactant conversion and selectivity. Despite the intrinsic unreducible nature, unreducible materials such as silica, alumina, hydroxyapatite, and carbon materials have advantages compared to the reducible metal oxides because of their earth-abundant storage, controllably adjusted morphology, easily manufactured surface property, and many other specific characteristics. Therefore, it is critical to investigate if unreducible materials can be used as common supports for $\mathrm{Au}$ NPs with comparable catalytic performances as those supported by reducible oxides. However, it is established that unreducible materials used as support leads to the drawback of inferior catalytic activity of gold catalyst due to their weak interaction between gold and support, as well as the unsatisfying

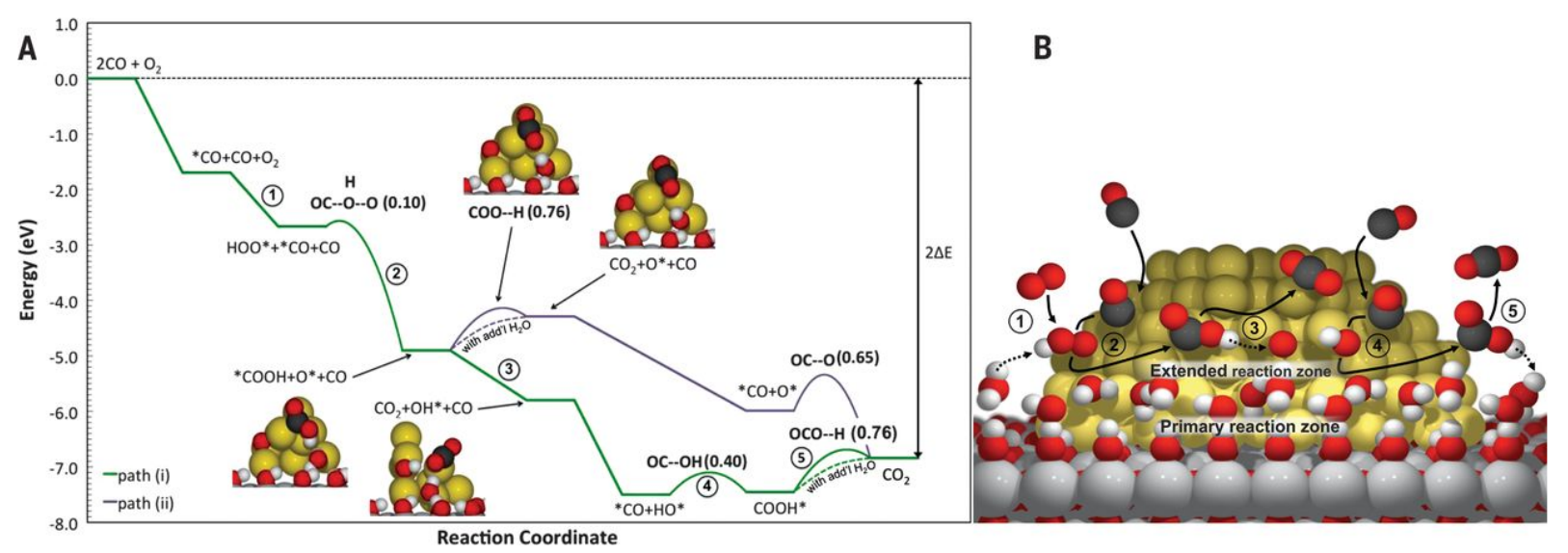

Fig. 19. (A) Effects of support water coverage on $\mathrm{CO}$ adsorption on Au. The blue region represents water adsorbed onto the support; (B) Schematic representation of the lower (green) pathway [189]. 
thermal stability. Investigation of various modifications of unreducible-material-supported Au NPs have been the focus during the past years.

Bimetallic systems or doping systems of unreducible-material-supported gold catalysts may be potentially applied as candidates that overcome the current limitations by combining the properties from multi-constituents. However, the durability of the gold catalysts still restricts their industrial application, in particular, in liquid phase oxidation when oxygen or air are used as the oxidant. Furthermore, a serious drawback for the industrial exploitation of current gold catalysts is the apparent need for the presence of a base. Besides, the defected structure of the Au catalyst is reported to be essential for changing the reaction rate by orders of magnitude, which varied along with the reaction process and no convincing research work has been reported. Although research work concerning gold on unreducible supports has emerged in recent years, there is still a necessity for research to thoroughly reveal the essence of gold catalysis. There are several major aspects of the tasks concerning the further investigation of gold on unreducible support systems. First, the real-case evolution of $\mathrm{Au}$ NPs and additional doping component during the reaction should be investigated. However, this operation is difficult in the supported bimetallic and even trimetallic systems. As it was reported that gold and metal oxide particles are likely to undergo evolution during thermal treatment and reaction atmosphere, the evolution of particles can be visualized ex-situ by techniques such as XPS, XRD, and TEM. However, such unresolved in situ variations have attracted ambitious attempts.
Environmental transmission electron microspectroscopy (ETEM) has been proven as an efficient technique that has emerged in recent years. It is assumed that the real face of gold on unreducible support with appropriate modifications will be investigated by the combination of in situ techniques and ETEM. Furthermore, a combination of theoretical calculations and experimental results should contribute to the better understanding of gold catalysis. In summary, the use and results from both macroscopic and microscopic studies should be conjunctively in for an in depth uniform comprehension of gold catalysis. To conclude, research must be continued until large-scale application of gold becomes possible, which is a highly challenging task.

\section{References}

[1] M. Haruta, T. Kobayashi, H. Sano, N. Yamada, Chem. Lett., 1987, 405-408.

[2] J. B. Zhao, R. C. Jin, Nano Today, 2018, 18, 86-102.

[3] D. Pflasterer, A. S. K. Hashmi, Chem. Soc. Rev., 2016, 45, 1331-1367.

[4] W. Li, B. Yu, Chem. Soc. Rev., 2018, 47, 7954-7984.

[5] C. M. Friend, B. J. Xu, Acc. Chem. Res., 2017, 50, 517-521.

[6] Q. Y. Wang, K. L. Yeung, M. A. Banares, J. Catal., 2018, 364, 80-88.

[7] J. L. Yang, C. Y. Mou, Appl. Catal. B, 2018, 231, 283-291.

[8] T. H. Tan, R. J. Wong, J. Scott, Y. H. Ng, R. A. Taylor, K. F. Aguey-Zinsou, R. Amal, ACS Catal., 2018, 8, 7158-7163.

[9] L. Shi, Z. Li, T. D. Dao, T. Nagao, Y. Yang, J. Mater. Chem. A, 2018, 6, 12978-12984.

[10] Z. H. Lu, H. L. Jiang, M. Yadav, K. Aranishi, Q. Xu, J. Mater. Chem.,

\section{Graphical Abstract}

Chin. J. Catal., 2021, 42: 670-693 doi: 10.1016/S1872-2067(20)63743-3

\section{Development of gold catalysts supported by unreducible materials: Design and promotions}

Jingjie Luo, Yanan Dong, Corinne Petit, Changhai Liang*

Dalian University of Technology, China; University of Strasbourg, France

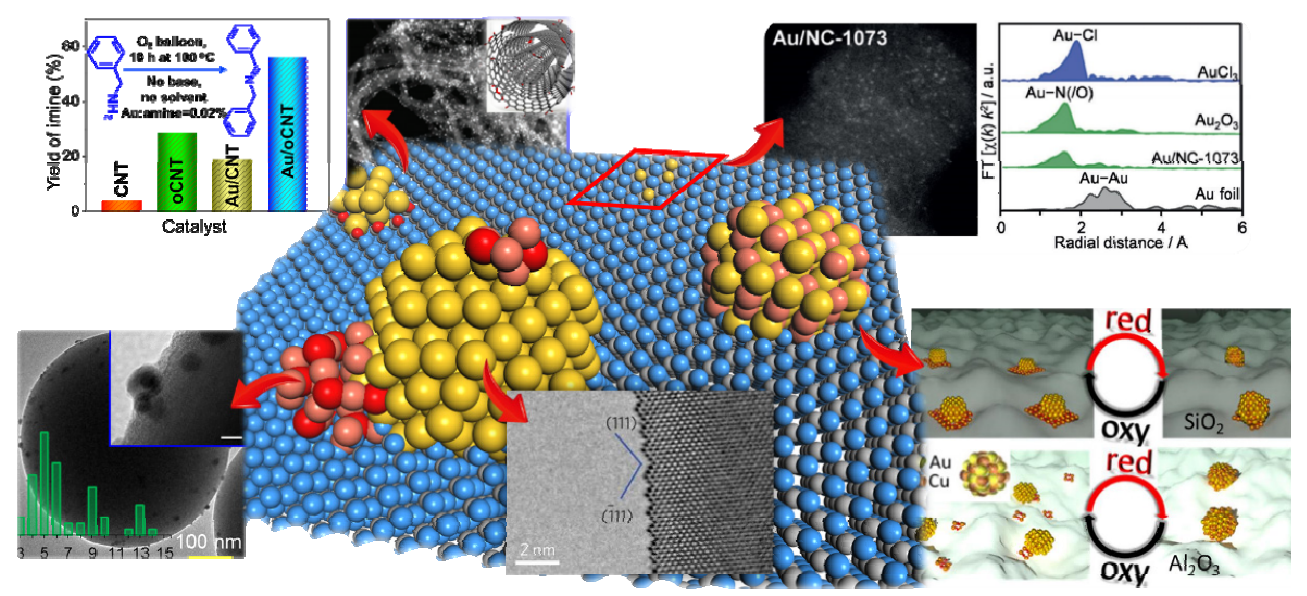

Reports on the use of gold supported by unreducible materials (e.g., C, $\mathrm{SiO}_{2}, \mathrm{Al}_{2} \mathrm{O}_{3}$, and hydroxyapatite) are systematically reviewed. Currently prevailing modification strategies are summarized from both the aspects of theoretical conceptualization and practical methodology. 
2012, 22, 5065-5071.

[11] S. H. Xie, H. Tsunoyama, W. Kurashige, Y. Negishi, T. Tsukuda, ACS Catal., 2012, 2, 1519-1523.

[12] N. N. M. Ghani, A. A. Jalil, S. Triwahyono, M. A. A. Aziz, A. F. A. Rahman, M. Y. S. Hamid, S. M. Izan, M. G. M. Nawawi, Chem. Eng. Sci., 2019, 193, 217-229.

[13] Y. Yang, F. Yang, D. H. Zeng, Z. L. Huang, J. P. Zhang, S. J. Hao, X. G. Kong, Z. B. Zhang, B. J. Liu, J. Colloid Interf. Sci., 2018, 531, 291-299.

[14] J. Y. Dai, H. B. Zou, Z. Q. Shi, H. Q. Yang, R. W. Wang, Z. T. Zhang, S. L. Qiu, Acs Appl. Mater. Interfaces, 2018, 10, 33474-33483.

[15] L. Li, L. Dou, H. Zhang, Nanoscale, 2014, 6, 3753-3763.

[16] X. Kong, C. Wu, L. Feng, J. Qu, P. Liu, X. Wang, X. Zhang, Chem. Commun., 2017, 53, 8054-8057.

[17] S. Chen, H. Fu, L. Zhang, Y. Wan, Appl. Catal. B, 2019, 248, 22-30.

[18] A. Alazman, D. Belic, A. Alotaibi, E. F. Kozhevnikova, I. V. Kozhevnikov, ACS Catal., 2019, 9, 5063-5073.

[19] R. H. Lin, D. Albani, E. Fako, S. K. Kaiser, O. V. Safonova, N. Lopez, J. Perez-Ramirez, Angew. Chem. Int. Ed., 2019, 58, 504-509.

[20] P. Destro, T. M. Kokumai, A. Scarpellini, L. Pasquale, L. Manna, M. Colombo, D. Zanchet, ACS Catal., 2018, 8, 1031-1037.

[21] J. Luo, O. Ersen, W. Chu, T. Dintzer, P. Petit, C. Petit, J. Colloid Interf. Sci., 2016, 482, 135-141.

[22] T. Fujita, P. F. Guan, K. McKenna, X. Y. Lang, A. Hirata, L. Zhang, T. Tokunaga, S. Arai, Y. Yamamoto, N. Tanaka, Y. Ishikawa, N. Asao, Y. Yamamoto, J. Erlebacher, M. W. Chen, Nat. Mater., 2012, 11, 775-780.

[23] A. S. K. Hashmi, Chem. Rev., 2007, 107, 3180-3211.

[24] Z. Ma, S. Dai, ACS Catal., 2011, 1, 805-818.

[25] X. Y. Liu, A. Wang, T. Zhang, C.-Y. Mou, Nano Today, 2013, 8, 403-416.

[26] T. Mallat, A. Baiker, Chem. Rev., 2004, 104, 3037-3058.

[27] J. J. Luo, W. Chu, S. Sall, C. Petit, Colloids Surf. A, 2013, 425, 83-91.

[28] J. Luo, H. Wei, Y. Liu, D. Zhang, B. Zhang, W. Chu, C. Pham-Huu, D. S. Su, Chem. Commun., 2017, 53, 12750-12753.

[29] E. del Rio, S. E. Collins, A. Aguirre, X. W. Chen, J. J. Delgado, J. J. Calvino, S. Bernal, J. Catal., 2014, 316, 210-218.

[30] X. Li, S. S. S. Fang, J. Teo, Y. L. Foo, A. Borgna, M. Lin, Z. Zhong, ACS Catal, 2012, 2, 360-369.

[31] Y. Hao, M. Mihaylov, E. Ivanova, K. Hadjiivanov, H. Knozinger, B. C. Gates, J. Catal., 2009, 261, 137-149.

[32] T. A. Ntho, J. A. Anderson, M. S. Scurrell, J. Catal, 2009, 261, 94-100.

[33] J. J. Luo, Y. F. Liu, Y. M. Niu, Q. Jiang, R. Huang, B. S. Zhang, D. S. Su, Nanoscale, 2017, 9, 15033-15043.

[34] E. Quinet, F. Morfin, F. Diehl, P. Avenier, V. Caps, J. L. Rousset, Appl. Catal. B, 2008, 80, 195-201.

[35] Z. Li, Y. Ji, C. Cadigan and R. M. Richards, Catal Sci Technol, 2014, 4, 2520-2525.

[36] L. S. Roselin, L. M. Liao, F. W. Chang, J. Nanosci. Nanotechnol, 2017, 17, 2796-2803.

[37] M. Okumura, S. Nakamura, S. Tsubota, T. Nakamura, M. Azuma, M. Haruta, Catal. Lett., 1998, 51, 53-58.

[38] X. Z. Shu, S. C. Nguyen, Y. He, F. Oba, Q. Zhang, C. Canlas, G. A. Somorjai, A. P. Alivisatos, F. D. Toste, J. Am. Chem. Soc., 2015, 137, 7083-7086.

[39] R. Ye, A. V. Zhukhovitskiy, R. V. Kazantsev, S. C. Fakra, B. B. Wickemeyer, F. D. Toste, G. A. Somorjai, J. Am. Chem. Soc., 2018, 140, 4144-4149.

[40] D. Gu, C. J. Jia, C. Weidenthaler, H. J. Bongard, B. Spliethoff, W. Schmidt, F. Schuth, J. Am. Chem. Soc., 2015, 137, 11407-11418.

[41] H. G. Zhu, C. D. Liang, W. F. Yan, S. H. Overbury, S. Dai, J. Phys. Chem. $B, 2006,110,10842-10848$.
[42] M. Yang, S. Li, Y. Wang, J. A. Herron, Y. Xu, L. F. Allard, S. Lee, J. Huang, M. Mavrikakis, M. Flytzani-Stephanopoulos, Science, 2014, 346, 1498-1501.

[43] Y. M. Lin, X. Y. Sun, D. S. Su, G. Centi, S. Perathoner, Chem. Soc. Rev., 2018, 47, 8438-8473.

[44] W. Y. Chen, Z. J. Wang, X. Z. Duan, G. Qian, D. Chen, X. G. Zhou, Chem. Eng. Sci., 2018, 192, 1242-1251.

[45] C. Ruiz-Garcia, F. Heras, L. Calvo, N. Alonso-Morales, J. J. Rodriguez, M. A. Gilarranz, Appl. Catal. B, 2018, 238, 609-617.

[46] X. Y. Shu, Q. Yang, F. B. Yao, Y. Zhong, W. C. Ren, F. Chen, J. Sue, Y. H. Ma, Z. Y. Fe, D. B. Wang, X. M. Li, Chem. Eng. J., 2019, 358, 903-911.

[47] H. Y. Liu, L. Y. Zhang, N. Wang, D. S. Su, Angew. Chem. Int. Ed., 2014, $53,12634-12638$.

[48] J. Luo, E. Qu, Y. Zhou, Y. Dong, C. Liang, Appl. Catal. A, 2020, 602, 117669.

[49] G. Malta, S. A. Kondrat, S. J. Freakley, C. J. Davies, L. Lu, S. Dawson, A. Thetford, E. K. Gibson, D. J. Morgan, W. Jones, P. P. Wells, P. Johnston, C. R. A. Catlow, C. J. Kiely, G. J. Hutchings, Science, 2017, 355, 1399-1402.

[50] A. Seral-Ascaso, A. Luquin, M. J. Lazaro, G. F. de la Fuente, M. Laguna, E. Munoz, Appl. Catal. A, 2013, 456, 88-95.

[51] J. Xu, J. Zhao, J. Xu, T. Zhang, X. Li, X. Di, J. Ni, J. Wang, J. Cen, Ind. Eng. Chem. Res., 2014, 53, 14272-14281.

[52] E. G. Rodrigues, M. F. R. Pereira, X. Chen, J. J. Delgado, J. J. M. Órfão, J. Catal., 2011, 281, 119-127.

[53] P. R. Murthy, P. Selvam, Chem. Rec., 2018, 18, 1-14.

[54] J. Sá, A. Goguet, S. F. R. Taylor, R. Tiruvalam, C. J. Kiely, M. Nachtegaal, G. J. Hutchings, C. Hardacre, Angew. Chem. Int. Ed., 2011, 50, 8912-8916.

[55] J. Qi, L. Xin, D. J. Chadderdon, Y. Qiu, Y. Jiang, N. Benipal, C. Liang, W. Li, Appl. Catal. B, 2014, 154-155, 360-368.

[56] D. Terada, T. F. Segawa, A. I. Shames, S. Onoda, T. Ohshima, E. Ōsawa, R. Igarashi, M. Shirakawa, ACS Nano, 2019, 13, 6461-6468.

[57] G. Reina, L. Zhao, A. Bianco, N. Komatsu, Angew. Chem. Int. Ed., 2019, 58, 2-14.

[58] H. Y. Liu, J. Y. Diao, Q. Wang, S. Y. Gu, T. Chen, C. X. Miao, W. M. Yang, D. S. Su, Chem. Commun., 2014, 50, 7810-7812.

[59] H. Ba, J. J. Luo, Y. F. Liu, D. V. Cuong, G. Tuci, G. Giambastiani, J. M. Nhut, N. D. Lam, O. Ersen, D. S. Su, P. H. Cuong, Appl. Catal. B, 2017, 200, 343-350.

[60] L. Y. Zhang, H. Y. Liu, X. Huang, X. P. Sun, Z. Jiang, R. Schlogl, D. S. Su, Angew. Chem. Int. Ed., 2015, 54, 15823-15826.

[61] D. Santiago, G. G. Rodriguez-Calero, A. Palkar, D. Barraza-Jimenez, D. H. Galvan, G. Casillas, A. Mayoral, M. Jose-Yacaman, L. Echegoyen, C. R. Cabrera, Langmuir, 2012, 28, 17202-17210.

[62] M. C. Kim, D. Lee, S. H. Jeong, S. Y. Lee, E. Kang, ACS Appl. Mater. Interfaces, 2016, 8, 34317-34326.

[63] J. C. Wang, S. A. Kondrat, Y. Y. Wang, G. L. Brett, C. Giles, J. K. Bartley, L. Lu, Q. Liu, C. J. Kiely, G. J. Hutchings, ACS Catal., 2015, 5, 3575-3587.

[64] M. M. Zhang, X. Lu, H. Y. Wang, X. L. Liu, Y. J. Qin, P. Zhang, Z. X. Guo, RSC Adv., 2016, 6, 35945-35951.

[65] S. Zhang, Y. Y. Shao, H. G. Liao, J. Liu, I. A. Aksay, G. P. Yin, Y. H. Lin, Chem. Mater., 2011, 23, 1079-1081.

[66] L. D. Shao, X. Huang, D. Teschner, W. Zhang, ACS Catal., 2014, 4, 2369-2373.

[67] H. L. Tang, F. Liu, J. K. Wei, B. T. Qiao, K. F. Zhao, Y. Su, C. Z. Jin, L. Li, J. Y. Liu, J. H. Wang, T. Zhang, Angew. Chem. Int. Ed., 2016, 55, 10606-10611.

[68] H. Tang, J. Wei, F. Liu, B. Qiao, X. Pan, L. Li, J. Liu, J. Wang, T. Zhang, J. Am. Chem. Soc., 2016, 138, 56-59. 
[69] M. I. Dominguez, F. Romero-Sarria, M. A. Centeno, J. A. Odriozola, Appl. Catal. B, 2009, 87, 245-251.

[70] Y. Wang, B. B. Chen, M. Crocker, Y. J. Zhang, X. B. Zhu, C. Shi, Catal. Commun., 2015, 59, 195-200.

[71] H. L. Tang, Y. Su, Y. L. Guo, L. L. Zhang, T. B. Li, K. T. Zang, F. Liu, L. Li, J. Luo, B. T. Qiao, J. H. Wang, Chem. Sci., 2018, 9, 6679-6684.

[72] A. Jouve, G. Nagy, F. Somodi, C. Tiozzo, A. Villa, A. Balerna, A. Beck, C. Evangelisti, L. Prati, J. Catal., 2018, 368, 324-335.

[73] J. L. Ma, Z. W. Liu, J. L. Song, L. X. Zhong, D. Q. Xiao, H. X. Xi, X. H. Li, R. C. Sun, X. W. Peng, Green. Chem., 2018, 20, 5188-5195.

[74] S. M. Kim, J. H. Mun, S. W. Lee, H. An, H. Y. Kim, S. O. Kim, J. Y. Park, Chem. Commun., 2018, 54, 13734-13737.

[75] L. X. Dien, T. Ishida, A. Taketoshi, D. Q. Truong, H. D. Chinh, T. Honma, T. Murayama, M. Haruta, Appl. Catal. B, 2019, 241, 539-547.

[76] Y. Soni, I. Kavya, T. G. Ajithkumar, C. P. Vinod, Chem. Commun., 2018, 54, 12412-12415.

[77] X. F. Yang, A. Q. Wang, B. T. Qiao, J. Li, J. Y. Liu, T. Zhang, Acc. Chem. Res., 2013, 46, 1740-1748.

[78] R. H. Ouyang, J. X. Liu, W. X. Li, J. Am. Chem. Soc., 2013, 135, 1760-1771.

[79] T. W. Hansen, A. T. DelaRiva, S. R. Challa, A. K. Datye, Acc. Chem. Res., 2013, 46, 1720-1730.

[80] S. F. Fu, Y. Zheng, X. B. Zhou, Z. M. Ni, S. J. Xia, J. Hazard. Mater., 2019, 363, 41-54.

[81] P. Ilgin, O. Ozay, H. Ozay, Appl. Catal. B, 2019, 241, 415-423.

[82] S. Kameoka, M. Krajci, A. P. Tsai, Appl. Catal. A, 2019, 569, 101-109.

[83] T. Yan, D. W. Redman, W. Y. Yu, D. W. Flaherty, J. A. Rodriguez, C. B. Mullins, J. Catal., 2012, 294, 216-222.

[84] J. A. Rodriguez, S. Ma, P. Liu, J. Hrbek, J. Evans, M. Perez, Science, 2007, 318, 1757-1760.

[85] X. Y. Liu, A. Q. Wang, L. Li, T. Zhang, C. Y. Mou, J. F. Lee, J. Catal., 2011, 278, 288-296.

[86] Y. Yamada, C. K. Tsung, W. Huang, Z. Y. Huo, S. E. Habas, T. Soejima, C. E. Aliaga, G. A. Somorjai, P. D. Yang, Nat. Chem., 2011, 3, 372-376.

[87] C. J. Murphy, T. K. San, A. M. Gole, C. J. Orendorff, J. X. Gao, L. Gou, S. E. Hunyadi, T. Li, J. Phys. Chem. B, 2005, 109, 13857-13870.

[88] X. Y. Wan, C. M. Zhou, J. S. Chen, W. P. Deng, Q. H. Zhang, Y. H. Yang, Y. Wang, ACS Catal., 2014, 4, 2175-2185.

[89] H. J. Zhang, T. Watanabe, M. Okumura, M. Haruta, N. Toshima, Nat. Mater., 2012, 11, 49-52.

[90] B. Ballarin, D. Barreca, E. Boanini, M. C. Cassani, P. Dambruoso, A. Massi, A. Mignani, D. Nanni, C. Parise, A. Zaghi, ACS Sustainable Chem. Eng., 2017, 5, 4746-4756.

[91] J. Ohyama, Y. Hayashi, K. Ueda, Y. Yamamoto, S. Arai, A. Satsuma, J. Phys. Chem. C, 2016, 120, 15129-15136.

[92] J. A. D. Gualteros, M. A. S. Garcia, A. G. M. da Silva, T. S. Rodrigues, E. G. Candido, F. A. E. Silva, F. C. Fonseca, J. Quiroz, D. C. de Oliveira, S. I. C. de Torresi, C. V. R. de Moura, P. H. C. Camargo, E. M. de Moura, J. Mater. Sci., 2019, 54, 238-251.

[93] P. Muthukumar, S. P. Anthony, New J. Chem., 2018, 42, 18794-18801.

[94] P. M. Arnal, M. Comotti, F. Schuth, Angew Chem. Int. Ed., 2006, 45, 8224-8227.

[95] T. Y. Chen, Y. F. Lei, Q. H. Yang, Y. E. Wu, J. Mater. Chem. A, 2017, 5, 3136-3139.

[96] J. Qu, H. Zhu, D. Chen, N. Li, Q. Xu, J. Xie, H. Li, J. He, J. Lu, ChemCatChem, 2018, 10, 837-842.

[97] H. Y. Liu, J. Wang, Z. B. Feng, Y. M. Lin, L. Y. Zhang, D. S. Su, Small, 2015, 11, 5059-5064.
[98] P. Kraszkiewicz, W. Mista, Catal. Commun., 2018, 110, 14-17.

[99] K. C. O’Connell, J. R. Monnier, J. R. Regalbuto, Appl. Catal. B, 2018, 225, 264-272.

[100] K. Qian, L. F. Luo, H. Z. Bao, Q. Hua, Z. Q. Jiang, W. X. Huang, Catal. Sci. Technol., 2013, 3, 679-687.

[101] K. Qian, W. X. Huang, Catal. Today, 2011, 164, 320-324.

[102] K. Qian, W. H. Zhang, H. X. Sun, J. Fang, B. He, Y. S. Ma, Z. Q. Jiang, S. Q. Wei, J. L. Yang, W. X. Huang, J. Catal., 2011, 277, 95-103.

[103] C. Z. Wu, G. Bertoni, S. Marras, L. Manna, M. Colombo, ChemCatChem, 2017, 9, 2952-2960.

[104] C. L. Bianchi, P. Canton, N. Dimitratos, F. Porta, L. Prati, Catal. Today, 2005, 102-103, 203-212.

[105] D. Wang, A. Villa, F. Porta, D. S. Su, L. Prati, Chem. Commun., 2006, 1956-1958.

[106] Y. Yu, Q. B. Zhang, J. P. Xie, X. M. Lu, J. Y. Lee, Nanoscale, 2011, 3, 1497-1500.

[107] H. Tsunoyama, H. Sakurai, T. Tsukuda, Chem. Phys. Lett., 2006, 429, 528-532.

[108] R. Y. Zhong, K. Q. Sun, Y. C. Hong, B. Q. Xu, ACS Catal., 2014, 4, 3982-3993.

[109] G.-R. Zhang, B.-Q. Xu, Nanoscale, 2010, 2, 2798-2804.

[110] A. Quintanilla, V. C. L. Butselaar-Orthlieb, C. Kwakernaak, W. G. Sloof, M. T. Kreutzer, F. Kapteijn, J. Catal., 2010, 271, 104-114.

[111] H. Tsunoyama, N. Ichikuni, H. Sakurai, T. Tsukuda, J. Am. Chem. Soc., 2009, 131, 7086-7093.

[112] J. A. Lopez-Sanchez, N. Dimitratos, C. Hammond, G. L. Brett, L. Kesavan, S. White, P. Miedziak, R. Tiruvalam, R. L. Jenkins, A. F. Carley, D. Knight, C. J. Kiely, G. J. Hutchings, Nat. Chem., 2011, 3, 551-556.

[113] R.-Y. Zhong, X.-H. Yan, Z.-K. Gao, R.-J. Zhang, B.-Q. Xu, Catal. Sci. Technol., 2013, 3, 3013-3019.

[114] S. M. Ansar, F. S. Ameer, W. Hu, S. Zou, C. U. Pittman, D. Zhang, Nano Lett., 2013, 13, 1226-1229.

[115] E. Quinet, L. Piccolo, F. Morfin, P. Avenier, F. Diehl, V. Caps, J. L. Rousset, J. Catal., 2009, 268, 384-389.

[116] T. E. Parmentier, S. R. Dawson, G. Malta, L. Lu, T. E. Davies, S. A. Kondrat, S. J. Freakley, C. J. Kiely, G. J. Hutchings, ChemCatChem, 2018, 10, 1853-1859.

[117] N. Dimitratos, A. Villa, D. Wang, F. Porta, D. S. Su, L. Prati, J. Catal., 2006, 244, 113-121.

[118] J. Luo, Y. Liu, H. Wei, B. Wang, K.-H. Wu, B. Zhang, D. S. Su, Green Chem., 2017, 19, 1052-1062.

[119] X. M. Liao, W. Chu, X. Y. Dai, V. Pitchon, Appl. Catal. B, 2013, 142, 25-37.

[120] W. Wittanadecha, N. Laosiripojana, A. Ketcong, N. Ningnuek, P. Praserthdam, J. R. Monnier, S. Assabumrungrat, Appl. Catal. A, 2014, 475, 292-296.

[121] A. Taketoshi, T. Ishida, H. Ohashi, T. Honma, M. Haruta, Chin. J. Catal., 2017, 38, 1888-1898.

[122] S. Futamura, A. H. Zhang, T. Yamamoto, J. Electrostat., 1997, 42, 51-62.

[123] K.-P. Francke, H. Miessner, R. Rudolph, Plasma Chem. Plasma P., 2000, 20, 393-403.

[124] K. Yu, Z. Wen, H. Pu, G. Lu, Z. Bo, H. Kim, Y. Qian, E. Andrew, S. Mao, J. Chen, J. Mater. Chem. A, 2013, 1, 188-193.

[125] A. Y. Khodakov, W. Chu, P. Fongarland, Chem. Rev., 2007, 107, 1692-1744.

[126] W. Chu, L. N. Wang, P. A. Chernavskii, A. Y. Khodakov, Angew. Chem. Int. Ed., 2008, 47, 5052-5055.

[127] D. Van Thanh, L. J. Li, C. W. Chu, P. J. Yen, K. H. Wei, RSC Adv., 2014, 4, 6946-6949.

[128] I. Suarez-Martinez, C. Bittencourt, X. Ke, A. Felten, J. J. Pireaux, J. 
Ghijsen, W. Drube, G. Van Tendeloo, C. P. Ewels, Carbon, 2009, $47,1549-1554$.

[129] R. Ionescu, E. H. Espinosa, E. Sotter, E. Llobet, X. Vilanova, X. Correig, A. Felten, C. Bittencourt, G. Van Lier, J. C. Charlier, J. J. Pireaux, Sensor Actuat. B, 2006, 113, 36-46.

[130] H. Y. Xu, J. J. Luo, W. Chu, RSC Adv., 2014, 4, 25729-25735.

[131] N. K. Gamboa-Rosales, J. L. Ayastuy, M. P. González-Marcos, M. A. Gutiérrez-Ortiz, Int. J. Hydrogen Energy, 2012, 37, 7005-7016.

[132] S. A. Nikolaev, E. V. Golubina, I. N. Krotova, M. I. Shilina, A. V. Chistyakov, V. V. Kriventsov, Appl. Catal. B, 2015, 168-169, 303-312.

[133] C. George, A. Genovese, A. Casu, M. Prato, M. Povia, L. Manna, T. Montanari, Nano Lett., 2013, 13, 752-757.

[134] J. K. Edwards, S. J. Freakley, A. F. Carley, C. J. Kiely, G. J. Hutchings, Acc Chem. Res., 2014, 47, 845-854.

[135] L. Kesavan, R. Tiruvalam, M. H. A. Rahim, M. I. bin Saiman, D. I. Enache, R. L. Jenkins, N. Dimitratos, J. A. Lopez-Sanchez, S. H. Taylor, D. W. Knight, C. J. Kiely, G. J. Hutchings, G. J., Science, 2011, 331, 195-199.

[136] D. M. Alonso, S. G. Wettstein, J. A. Dumesic, Chem. Soc. Rev., 2012, 41, 8075-8098.

[137] B. Pawelec, A. M. Venezia, V. La Parola, S. Thomas, J. L. G. Fierro, Appl. Catal. A, 2005, 283, 165-175.

[138] L. F. Yang, S. Y. Shan, R. Loukrakpam, V. Petkov, Y. Ren, B. N. Wanjala, M. H. Engelhard, J. Luo, J. Yin, Y. S. Chen, C. J. Zhong, J. Am. Chem. Soc., 2012, 134, 15048-15060.

[139] I. X. Green, W. J. Tang, M. Neurock, J. T. Yates, Science, 2011, 333, 736-739.

[140] R. P. Doherty, J.-M. Krafft, C. Méthivier, S. Casale, H. Remita, C. Louis, C. Thomas, J. Catal., 2012, 287, 102-113.

[141] Y. Sugano, Y. Shiraishi, D. Tsukamoto, S. Ichikawa, S. Tanaka, T. Hirai, Angew. Chem. Int. Ed., 2013, 52, 5295-5299.

[142] Q. Kang, T. Wang, P. Li, L. Liu, K. Chang, M. Li, J. Ye, Angew. Chem. Int. Ed., 2015, 54, 841-845.

[143] R. Su, R. Tiruvalam, A. J. Logsdail, Q. He, C. A. Downing, M. T. Jensen, N. Dimitratos, L. Kesavan, P. P. Wells, R. Bechstein, H. H. Jensen, S. Wendt, C. R. A. Catlow, C. J. Kiely, G. J. Hutchings, F. Besenbacher, ACS Nano, 2014, 8, 3490-3497.

[144] H. Zhang, T. Watanabe, M. Okumura, M. Haruta, N. Toshima, Nat. Mater., 2012, 11, 49-52.

[145] N. El Kolli, L. Delannoy, C. Louis, J. Catal, 2013, 297, 79-92.

[146] A. Hugon, L. Delannoy, J. M. Krafft, C. Louis, J. Phys. Chem. C, 2010, 114, 10823-10835.

[147] T. Ward, L. Delannoy, R. Hahn, S. Kend ell, C. J. Pursell, C. Louis, B. D. Chandler, ACS Catal., 2013, 3, 2644-2653.

[148] S. J. Tauster, S. C. Fung, R. L. Garten, J. Am. Chem. Soc., 1978, 100, $170-175$.

[149] Q. Fu, T. Wagner, S. Olliges, H. D. Carstanjen, J. Phys. Chem. B, 2005, 109, 944-951.

[150] X. Y. Liu, M. H. Liu, Y. C. Luo, C. Y. Mou, S. D. Lin, H. K. Cheng, J. M. Chen, J. F. Lee, T. S. Lin, J. Am. Chem. Soc., 2012, 134, 10251-10258.

[151] J. Huang, L. C. Wang, Y. M. Liu, Y. Cao, H. Y. He, K. N. Fan, Appl. Catal. B, 2011, 101, 560-569.

[152] J. Wang, A. H. Lu, M. R. Li, W. P. Zhang, Y. S. Chen, D. X. Tian, W. C. Li, ACS Nano, 2013, 7, 4902-4910.

[153] E. Pizzutilo, S. J. Freakley, S. Cherevko, S. Venkatesan, G. J. Hutchings, C. H. Liebscher, G. Dehm, K. J. J. Mayrhofer, ACS Catal., 2017, 7, 5699-5705.

[154] M. Boronat, A. Corma, Dalton Trans., 2010, 39, 8538-8546.

[155] J. K. Norskov, F. Abild-Pedersen, Nature, 2009, 461, 1223-1225.

[156] I. Lee, F. Delbecq, R. Morales, M. A. Albiter, F. Zaera, Nat. Mater.,
2009, 8, 132-138.

[157] R. A. Van Santen, Acc. Chem. Res., 2009, 42, 57-66.

[158] R. J. H. Grisel, B. E. Neiuwenhuys, Catal. Today, 2001, 64, 69-81.

[159] S. Wang, J. Wang, Q. F. Zhao, D. D. Li, J. Q. Wang, M. Cho, H. Cho, O. Terasaki, S. J. Chen, Y. Wan, ACS Catal., 2015, 5, 797-802.

[160] B. Solsona, T. Garcia, E. Aylon, A. M. Dejoz, I. Vazquez, S. Agouram, T. E. Davies, S. H. Taylor, Chem. Eng. J., 2011, 175, 271-278.

[161] M. Gasior, B. Grzybowska, K. Samson, M. Ruszel, J. Haber, Catal. Today, 2004, 91-92, 131-135.

[162] M. Kipnis, Appl. Catal. B, 2014, 152, 38-45.

[163] B. T. Qiao, A. Q. Wang, X. F. Yang, L. F. Allard, Z. Jiang, Y. T. Cui, J. Y. Liu, J. Li, T. Zhang, Nat. Chem., 2011, 3, 634-641.

[164] L. L. Zhang, Y. J. Ren, W. G. Liu, A. Q. Wang, T. Zhang, Natl. Sci. Rev., 2018, 5, 653-672.

[165] B. Han, R. Lang, B. T. Qiao, A. Q. Wang, T. Zhang, Chin. J. Catal., 2017, 38, 1498-1507.

[166] M. F. Camellone, S. Fabris, J. Am. Chem. Soc., 2009, 131, 10473-10483.

[167] Y. G. Wang, D. H. Mei, V. A. Glezakou, J. Li, R. Rousseau, Nat. Commun., 2015, 6, 6511.

[168] C. Y. Wang, G. Garbarino, L. F. Allard, F. Wilson, G. Busca, M. Flytzani-Stephanopoulos, ACS Catal., 2016, 6, 210-218.

[169] A. Corma, O. G. Salnikov, D. A. Barskiy, K. V. Kovtunov, I. V. Koptyug, Chem.-Eur. J., 2015, 21, 7012-7015.

[170] Z. Chen, Y. J. Chen, S. L. Chao, X. B. Dong, W. X. Chen, J. Luo, C. G. Liu, D. S. Wang, C. Chen, W. Li, J. Li, Y. D. Li, ACS Catal., 2020, 10, 1865-1870.

[171] G. X. Zhu, J. T. Liu, Y. Z. Wang, D. C. Zhang, Y. Guo, E. Tasciotti, Z. B. Hu, X. W. Liu, ACS Appl. Mater. Interfaces, 2016, 8, 11881-11891.

[172] K. W. Smith, J. Yang, T. Hernandez, D. F. Swearer, L. Scarabelli, H. Zhang, H. Q. Zhao, N. A. Moringo, W. S. Chang, L. M. Liz-Marzan, E. Ringe, P. Nordlander, S. Link, J. Phys. Chem. C, 2018, 122, 13259-13266.

[173] C. H. Christensen, J. K. Norskov, Science, 2010, 327, 278-279.

[174] A. Wittstock, V. Zielasek, J. Biener, C. M. Friend, M. Baumer, Science, 2010, 327, 319-322.

[175] C. Wang, H. F. Yin, S. Dai, S. H. Sun, Chem. Mater., 2010, 22, 3277-3282.

[176] F. H. Lin, W. Chen, Y. H. Liao, R. A. Doong, Y. D. Li, Nano Res., 2011, 4, 1223-1232.

[177] V. La Parola, M. Kantcheva, M. Milanova, A. M. Venezia, J. Catal., 2013, 298, 170-178.

[178] X. L. Wu, L. F. Tan, D. Chen, X. W. Meng, F. Q. Tang, Chem. Commun., 2014, 50, 539-541.

[179] P. N. Duchesne, Z. Y. Li, C. P. Deming, V. Fung, X. J. Zhao, J. Yuan, T. Regier, A. Aldalbahi, Z. Almarhoon, S. W. Chen, D. E. Jiang, N. F. Zheng, P. Zhang, Nat. Mater., 2018, 17, 1033-1039.

[180] R. C. Tiruvalam, J. C. Pritchard, N. Dimitratos, J. A. Lopez-Sanchez, J. K. Edwards, A. F. Carley, G. J. Hutchings, C. J. Kiely, Faraday Discuss., 2011, 152, 63-86.

[181] J. Luo, Y. Liu, L. Zhang, Y. Ren, S. Miao, B. Zhang, D. S. Su, C. Liang, ACS Appl. Mater. Interfaces, 2019, 11, 35468-35478.

[182] J. Luo, Y. Liu, Y. Niu, Q. Jiang, R. Huang, B. Zhang, D. Su, Nanoscale, 2017, 9, 15033-15043.

[183] L. Guczi, K. Frey, A. Beck, B. Peto, C. S. Daroczi, N. Kruse, S. Chenakin, Appl. Catal. A, 2005, 291, 116-125.

[184] J. Ji, Z. Lu, Yu Lei, C. H. Turner, Chem. Eng. Sci., 2018, 191, 169-182.

[185] T. Fujitani, I. Nakamura, Angew. Chem. Int. Ed., 2011, 50, 10144-10147.

[186] I. X. Green, W. J. Tang, M. McEntee, M. Neurock, J. T. Yates, J. Am. Chem. Soc., 2012, 134, 12717-12723. 
[187] H. L. Guan, J. Lin, L. Li, X. D. Wang, T. Zhang, Appl. Catal. B, 2016, 184, 299-308.

[188] B. N. Zope, D. D. Hibbitts, M. Neurock, R. J. Davis, Science, 2010, $330,74-78$

[189] J. Saavedra, H. A. Doan, C. J. Pursell, L. C. Grabow, B. D. Chandler,
Science, 2014, 345, 1599-1602.

[190] J. Saavedra, C. J. Pursell, B. D. Chandler, J. Am. Chem. Soc., 2018, 140, 3712-3723.

[191] G. M. Mullen, J. Gong, T. Yan, M. Pan, C. B. Mullins, Top. Catal., 2013, 56, 1499-1511.

\title{
不可还原材料负载的纳米金催化剂: 理性设计与优化

\author{
罗靖洁 ${ }^{\mathrm{a}}$, 董亚南 ${ }^{\mathrm{a}}$, Corinne Petit ${ }^{\mathrm{b}}$, 梁长海, ${ }^{\mathrm{a}}{ }^{*}$ \\ ${ }^{\mathrm{a}}$ 大连理工大学化工学院, 高级材料与催化工程实验室, 辽宁盘锦 124221 , 中国 \\ b 斯特拉斯堡大学, 能源环境健康化学过程所, 斯特拉斯堡 67087 , 法国
}

\begin{abstract}
摘要: 近年来, 负载型金催化剂被视为多相催化工业化进程中的机遇和挑战, 因而广受研究. 载体的选取可以有效调控纳 米金催化剂的化学结构及催化活性. 针对载体本身对反应是否具有活性, 可将其分为活性载体与惰性载体. 活性载体主要 为具有还原性的金属氧化物; 而惰性载体, 诸如碳基材料、氧化硅、氧化铝等, 多为反应条件下不具备还原性或不可进行 还原处理的材料, 不释放活性氧物种, 通常不具备显著催化活性. 一般情况下, 活性载体负载的金纳米粒子(Au NPs)在 CO 氧化反应、醇类选择性氧化反应、水煤气变换等多相催化反应中均展现出优越的催化活性及目标产物的选择性; 而以传 统不可还原性材料负载Au NPs时, 若非采用特殊的优化手段, 该类金催化剂的活性及稳定性通常差强人意. 尽管如此, 不 可还原材料作为惰性载体, 亦展现出无与伦比的独特优势, 例如其多具有易于调控的表面性能、可调变的多样化微观结构, 丰富的地壳储量和易于大规模产业化的优势等. 因此, 针对不可还原材料负载的纳米金催化剂, 探讨创新性的改性手段及 其对金催化剂活性与稳定性的理性调控, 成为近年来纳米金催化领域中最引人关注的研究课题之一. 然而到目前为止, 基 于惰性载体负载金催化剂的系统性总结工作仍未见报道. 作者及其所在团队围绕Au-载体/助剂表界面性质的精准调控及 理性验证, 以 $\mathrm{CO}$ 氧化与醇类选择氧化等反应为探针, 对基于不可还原材料的纳米金催化剂的设计理念和改性手段进行了 多尺度的探索. 基于本组研究工作及近十年相关文献报道, 本综述将以几种典型的不可还原材料为例, 针对负载型金催化 剂的研究进展进行详尽的阐述. 从催化剂设计的理论设想和实践方案入手, 对特殊结构材料的独创性研制手段、二元金属 掺杂及表面功能化手段、特殊氛围处理等备受关注的改性手段进行归纳. 并进一步对改性手段影响表面化学结构、电子 结构、 $\mathrm{Au}$-载体/助剂间的相互/协同作用、催化剂形貌的实例以及水物种参与对反应的影响等方面展开对比讨论. 本综述 旨在为致力于金催化研究工作及有志在该领域一展抱负的研究者拓展新的方向, 全面梌释不可还原材料作为惰性载体在 金催化领域的巨大应用前景, 进一步激发不可还原载体负载金催化剂开发的新思路, 推动纳米金催化的工业化进程.
\end{abstract}

关键词: 金催化剂; 不可还原性载体; 助剂修饰; 金-载体界面; 协同作用

收稿日期: 2020-04-26. 接受日期: 2020-06-14. 上网日期: 2020-09-22.

*通讯联系人. 电话/传真: (0411)84986353; 电子信箱: changhai@dlut.edu.cn

基金来源：国家自然科学基金(21573031，21802015，21978031); 大连市杰出人才项目(2016RD09); 中央高校启动经费 (DUT20RC(5)020).

本文的电子版全文由Elsevier出版社在ScienceDirect上出版(http://www.sciencedirect.com/science/journal/18722067). 